Math. Model. Nat. Phenom.

Vol. 3, No. 7, 2008, pp. 229-266

\title{
The Effects of HIV-1 Infection on Latent Tuberculosis
}

\author{
Amy L. Bauer ${ }^{a, b}$, Ian B. Hogue ${ }^{c}$, Simeone Marino ${ }^{c}$, and Denise E. Kirschner ${ }^{c 1}$ \\ ${ }^{a}$ Theoretical Division, Los Alamos National Laboratory, Los Alamos, New Mexico, 87545, USA \\ ${ }^{b}$ Department of Mathematics, University of Michigan, Ann Arbor, Michigan, 48109, USA \\ ${ }^{c}$ Department of Microbiology and Immunology, University of Michigan Medical School, \\ Ann Arbor, Michigan, 48109, USA
}

\begin{abstract}
Tuberculosis is the leading cause of death due to infectious diseases in the world today, and it is increasing due to co-infection with HIV-1, the causative agent of AIDS. Here, we examine the impact that HIV-1 infection has on persons with latent tuberculosis. Based on previous work, we develop a mathematical model of an adaptive immune response in the lung which considers relevant immune effectors such as macrophages, various sub-populations of T-cells, and key cytokines to predict which mechanisms are important to HIV-1 infection induced reactivation of tuberculosis. Our results indicate that persons latently infected with TB who are subsequently co-infected with HIV-1 will suffer reactive TB. The mechanisms that contribute to this are essentially related to a completely different cytokine environment at the onset of HIV-1 infection due to the presence of Mycobacterium tuberculosis. Our analysis suggests that macrophages play an important role during co-infection and decreases in macrophage counts are coupled to a decline in $\mathrm{CD}^{+}{ }^{+}$T-cells and increased viral loads. These mechanisms are also coupled to lower recruitment of T-cells and macrophages, compromising protective immunity in the lung and eventually leading to TB reactivation. These results point to potential targets for drug and vaccine therapies.
\end{abstract}

Key words: HIV, Mycobacterium tuberculosis, macrophages, uncertainty analysis, sensitivity analysis, mathematical model, immunology

AMS subject classification: 92D25

\footnotetext{
${ }^{1}$ Corresponding author. E-mail: kirschne@umich.edu
} 


\section{Introduction}

"The impact of HIV on tuberculosis (TB) has been devastating, with approximately $10 \%$ of all global cases now attributable to HIV - were it not for HIV, TB would already be declining worldwide" [43]. It has been estimated that over one-third of the world's population has latent TB [3][13]. TB is likely to continue to increase with the rising number of HIV infected individuals due to reactivation of latent TB and opportunistic infection by Mycobacterium tuberculosis (Mtb), the etiologic agent for tuberculosis [3]. Once infected with Mtb, 90-95\% of individuals progress to latent infection, where they show no clinical manifestations, and the infection is latent. In 5-10\% of cases, individuals are not able to control infection and active TB follows, that if not treated, usually results in lung destruction and death [12]. A person who has untreated active TB will infect 10-15 other persons per year [3]. An understanding of the mechanisms involved in the progression of TB and reactivation of latent TB that results from infection with HIV can have a profound effect on predicting the progression from HIV to AIDS, on the survivability of HIV infected persons through preventative treatment strategies, and on the control of TB worldwide.

\subsection{Immune Response to Intracellular Pathogens}

When viruses, bacteria or other pathogenic matter are introduced into the body, an immune response is necessary for control and clearance. Intracellular pathogens (like HIV-1 and M. tuberculosis), are cleared by a cell-mediated, adaptive immune response. There are two classes of T-cells that must be generated for this response: the helper T-cell (Th) and the cytotoxic T-cell. Cytotoxic T-cells, also known as killer T-cells or cytotoxic T-lymphocytes (CTLs), circulate through the bloodstream and the lymph and are capable of eliminating the pathogen by killing damaged or infected cells. The helper T-cell population is divided into Th1 helper and Th2 helper T-cells. Th1 helper T-cells assist in the generation of CTLs. Th2 helper T-cells assist in the generation of B-cells, which are most often engaged in fighting extracellular pathogens (not considered here). Another class of cells that are essential to a cell-mediated immune response are antigen presenting cells (APCs). The two main types of antigen presenting cells are macrophages and dendritic cells. In their normal state they both take up foreign antigen and present it to naive T-cells to generate helper T-cells. But once these APCs become activated by interacting with effector molecules and Th cells that are present at the infection site or in the lymph node, these APCs take on additional and different roles. For example, dendritic cells can then present antigen to $\mathrm{CD}^{+}{ }^{+} \mathrm{T}$-cells to generate CTLs, while activated macrophages can engulf and digest pathogens and continue to stimulate other immune cells to respond to the pathogens. This process is described in more detail in the next section. In addition, in response to antigen, T-cells and macrophages also release various effector molecules, known as cytokines, that influence cellular recruitment, activation, and function.

\subsection{Tuberculosis}

Tuberculosis is the leading cause of death in the world from a single infectious disease. TB is a highly infectious disease in the active state that is contracted most frequently by inhalation of tu- 
bercle bacteria in to the lung that is expelled by infected individuals through coughing [1]. Transmission depends on the source patient, the environment, the exposure time and the susceptible person [1]. Repeated, close contacts have been shown to be a key risk factor [1].

Bacteria enter the lung, which is typically the primary site of infection, where it is engulfed by macrophages during an innate immune response [10]. Mtb has a slow doubling time, approximately $15-20$ hours, and it prefers to live within macrophages. Bacteria are then transported by dendritic cells to the closest draining lymph nodes ( $\mathrm{LN})$ where the host's adaptive immune response is mounted against infection. In approximately $90 \%$ of cases, infection is contained within the lungs in small granulomatous lesions that form at the site of infection, known as granulomas [12]. Granulomas are comprised mainly of bacteria, infected and activated macrophages, dendritic cells and T-cells. Once adaptive immunity is present, Mtb has never been shown to be entirely eradicated from a host, but is likely harbored within granulomas when infection is considered latent. If the host's system later becomes immuno-compromised or perturbed in some way, it is generally thought that granuloma stability can be breached and Mtb can again be released. Often active disease ensues.

Since Mtb generally resides within macrophages, a T-cell mediated immune response rather than an antibody-mediated immune response is necessary to combat infection. Macrophages and dendritic cells initially take up the bacteria at the site of infection and transport bacteria or bacterial antigen to the draining $\mathrm{LN}$ where a specific immune response can be developed. In addition to APCs, $\mathrm{CD}^{+}$and $\mathrm{CD} 8^{+}$T-cells are also involved in the protective immune response against Mtb. During the initial weeks of infection, $\mathrm{CD}^{+}$and $\mathrm{CD}^{+}$T-cells are activated and increase in number in the lung-draining lymph nodes. $\mathrm{CD} 4^{+}$and $\mathrm{CD} 8^{+} \mathrm{T}$-cells then migrate to the site of infection where they interact with macrophages. These cells produce gamma interferon (IFN- $\gamma$ ) which activates macrophages to produce nitric oxide, a major antimicrobial mechanism [9]. Other important $\mathrm{CD}^{+} \mathrm{T}$-cell functions are to help in the activation and maintenance of $\mathrm{CD} 8^{+} \mathrm{T}$-cell effector and memory functions as well as the lysis of infected cells [6]. Activation of Mtb specific CD8 ${ }^{+}$CTLs, occurs in response to both infected cells and antigen presenting cells. CTLs are capable of lysing infected macrophages and can also produce IFN $-\gamma$ when they interact with Mtb infected APCs, although in much smaller concentrations than the IFN- $\gamma$ produced by $\mathrm{CD}^{+} \mathrm{T}-$-cells [51][30]. The cellular interactions during the immune response to Mtb infection are shown in Figure 1. In this figure, white circles represent non-pathogen specific immune cells and blue stars represent Mtb specific cells. An important part of a host immune response to any pathogen is the presence of cytokines, which regulate the cells involved in the immune response. The cytokine interleukin-12 (IL-12), which is produced by dendritic cells after phagocytosis of Mtb [20] and macrophages, induces $\mathrm{CD}^{+}{ }^{+} \mathrm{T}$-cell polarization to type 1 helper T-cells [33]. In addition, the various T-cell populations produce another crucial cytokine IFN $-\gamma$ that activates anti-mycobacterial macrophage functions, such as the production of nitric oxide mentioned above. Further, cytolytic proteins, such as perforin and granulysin, are produced by the $\mathrm{CD}^{+} \mathrm{T}$-cells that can directly kill Mtb residing within infected macrophages [53][54]. Through knock-out studies with mice, tumor necrosis factor- $\alpha$ (TNF- $\alpha$ ), which is produced by macrophages, T-cells and dendritic cells, acting as a co- 


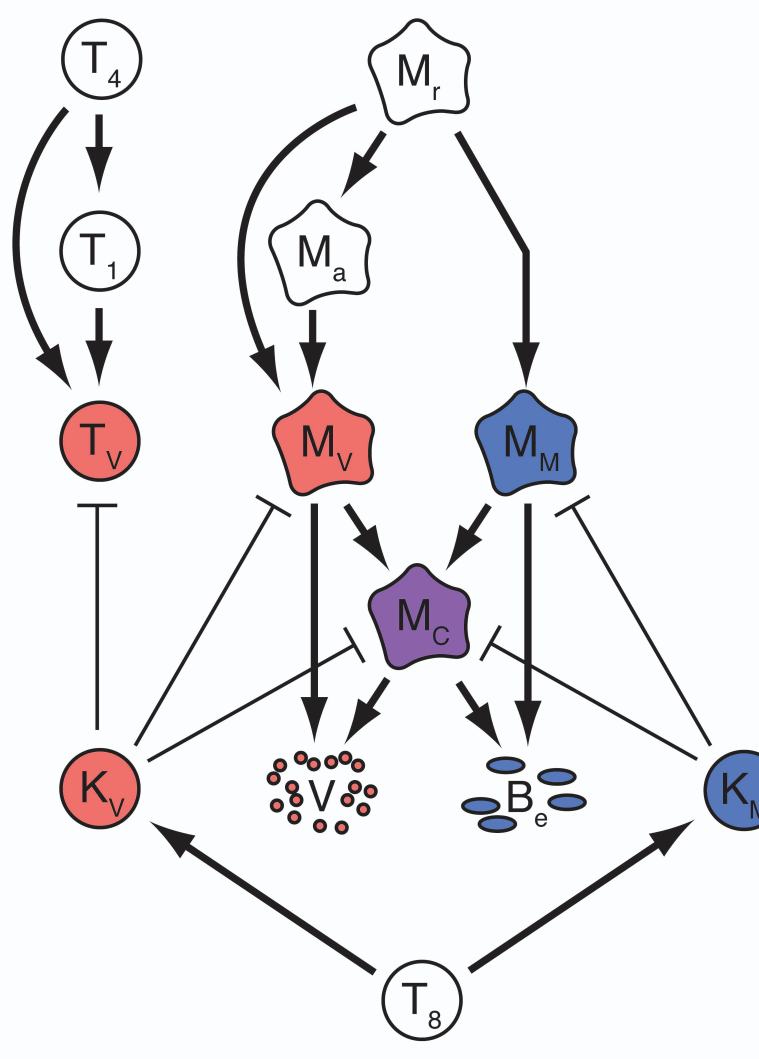

Figure 1: Schematic summarizing the main immune response mechanisms represented in HIV1/TB co-infection model. T-cell populations are depicted by circles, macrophage populations by stars. Immune cells that are non-specific to any particular pathogen are shown as white, Mtb related populations are colored blue, and HIV-1 related populations are shown as red. Co-infected macrophages are distinguished in purple. Arrows indicate activation or an interaction that increases population size, whereas a hammerhead denotes inhibition or a decrease in population. $T_{4}=\mathrm{CD}^{+}$T-cells, $T_{8}=\mathrm{CD}^{+} \mathrm{T}$-cells, $T_{1}=\mathrm{CD}^{+} \mathrm{T}$ helper cells, $T_{V}=$ HIV infected $\mathrm{CD}^{+}{ }^{+}$T-cells, $M_{r}=$ resting macrophages, $M_{a}$ = activated macrophages, $M_{V}=\mathrm{HIV}$ infected macrophages, $M_{M}=$ Mtb infected macrophages, $M_{C}=$ macrophages co-infected with $\mathrm{Mtb}$ and HIV, $K_{V}=$ HIV specific CD8 ${ }^{+}$CTLs, $K_{M}=\mathrm{Mtb}$ specific $\mathrm{CD}^{+}$CTLs, $V=\mathrm{HIV}, B_{e}=$ extracellular Mtb. 
stimulator of IFN- $-\gamma$ to induce macrophage activation, has been shown to be a potent mediator in bacterial containment and in the formation and maintenance of granulomas [17]. On the other hand, interleukin-10 (IL-10) production by macrophages and T-cells during the course of Mtb infection deactivates macrophages [21], inhibits $\mathrm{CD}^{+} \mathrm{T}$-cell responses [16], and down regulates IL-12 production [16], which consequently decreases IFN- $\gamma$ production. The importance of these negative regulators of immunity have only recently been elucidated [58]. One can easily see the complexities and interconnectivity of the immune response to $M$. tuberculosis and how an alteration in the competency of the immune system can disrupt its delicate balance (for better or for worse). Thus, understanding what keeps the system in balance is key to sustaining latent TB.

\subsection{Human Immunodeficiency Virus (HIV)}

Presently, there is no known cure for Acquired Immunodeficiency Syndrome or AIDS, the disease that results from an HIV-1 infection. HIV-1 is a virus that preferentially infects $\mathrm{CD}^{+}{ }^{+} \mathrm{T}-$-cells and macrophages that are critical to our immune system response [41], thereby compromising a host's ability to control infection. HIV is an RNA-containing virus that uses the enzyme reverse transcriptase to produce a DNA provirus that is inserted into host cell DNA, commonly referred to as a retrovirus [41]. Virus is transmitted through the exchange of HIV-1 infected blood, semen, or vaginal fluids. This transmission frequently occurs during sexual contact, by using needles that are not sterilized (tattooing, intravenous drug users, accidental needle pricks in a clinical setting), use of unsafe blood or blood products, and to infants born to HIV-infected mothers [40]. HIV disease progression has been divided into several distinct phases categorized largely by T-cell $\left(\mathrm{CD}^{+}\right)$ counts in the blood. On average, humans have approximately $1000 \mathrm{CD}^{+} \mathrm{T}$-cells per $\mathrm{mm}^{3}$ of blood [2]. First, there is the primary HIV infection where the $\mathrm{CD} 4^{+} \mathrm{T}-$-cell count drops dramatically, followed by an asymptomatic phase where T-cell numbers level off, and finally a progression to AIDS phase, where the $\mathrm{CD}^{+}{ }^{+}$T-cell counts drop below 200 per $\mathrm{mm}^{3}$. The initial infection often goes unnoticed because the symptoms resemble the common flu or routine infections and lasts only a few weeks up to two months. Persons with an asymptomatic HIV infection generally maintain normal health with a CD4 ${ }^{+} \mathrm{T}$-cell count usually greater than 500 cells $/ \mathrm{mm}^{3}$. On average, this phase lasts 10 years [7]. As a person's T-cell count continues to drop, they present early symptoms such as fever, fatigue, diarrhea, dermatitis, and recurring herpes simplex infections. The late symptomatic stage is characterized by a CD4+ count below 200 cells per $\mathrm{mm}^{3}$ of blood, and the risk of developing malignancies and opportunistic infections becomes very high. When a person's T-cell count falls below 50 cells $/ \mathrm{mm}^{3}$, they are classified as having progressed to AIDS and these patients usually present multiple opportunistic infections. While HIV-1 is a blood-borne pathogen, many organs of the body become infected over the course of the disease, including lymph nodes, liver, brain and lungs. It makes sense that the lung becomes a site of infection as all blood passes through the lung to become oxygenated and thus lung tissue is highly vascularized. In some studies, the lung has been shown to be a place of active viral replication [45][19]. Thus, the interaction with Mtb and HIV-1 in the lung may play a role in co-infection dynamics. We now explore this further. 


\subsection{The Role of HIV-1 in Tuberculosis}

HIV weakens the immune system; TB thrives in a weakened immune system. Each disease speeds the other's progress [4]. One-third of the world population is estimated to be infected with TB [13]. HIV-1 is the most powerful known risk factor for reactivation of latent TB infection to active disease [3]. A person with a latent TB infection, who then contracts HIV-1, is 800 times more likely to develop active TB disease than someone who has not been infected with HIV-1 [1]. TB is also a leading cause of death among people who are HIV-positive. These facts make it clear that HIV-1 infection has a significant impact on the reactivation of latent TB. It easily follows that as the number of HIV-1 infected individuals continues to increase worldwide, active TB could become even more of a serious problem, not just because it accelerates the progression of HIV-1 to AIDS, but also because it is itself a highly contagious disease [1].

When two pathogens are simultaneously involved, the immune response to one pathogen affects the response to another pathogen. Figure 1 shows the relationships between Mtb and HIV-1 specific cell populations during co-infection. During latent TB, Mtb is contained in granulomas the maintenance of which relies on a healthy immune system and largely on the proper functioning of $\mathrm{CD} 4^{+}$T-cells [56]. In HIV-1 infection, the $\mathrm{CD} 4^{+}$T-cells are not only depleted, but their function is also altered. Thus infection with $\mathrm{HIV}-1$ often causes latent TB to reactivate and progress to active disease [52]. Since HIV-1 infection causes $\mathrm{CD}^{+}$T-cell depletion, the progression of TB is rapid for co-infected individuals [3]. On the other hand, Mtb causes increased recruitment of $\mathrm{CD}^{+}$T-cells that are targets for HIV-1 infection, and production of cytokines, such as TNF, that increase the replication rate of the HIV-1 virus [57][23]. Studies of T lymphocyte counts in HIV-1, $\mathrm{Mtb}$, and co-infected patients revealed lower $\mathrm{CD}^{+}$and $\mathrm{CD} 8^{+} \mathrm{T}$-cell counts in co-infected patients than in those singly infected [46] with either HIV-1 or Mtb (see Table 1). Treatment of co-infected patients poses another difficulty. In [39], the effects of HIV-1/Mtb co-infection on CD4 ${ }^{+}$T-cell counts for patients treated for TB were measured. These data showed a pronounced initial $\mathrm{CD}^{+}$ T-cell deficit in co-infected individuals following TB treatment, and a slower increase in $\mathrm{CD}^{+}$ T-cell counts for co-infected patients as compared to those infected with TB alone. In addition to $\mathrm{CD} 4{ }^{+}$T-cells, macrophages are also important target cells for both HIV-1 and Mtb. Macrophages that were concurrently infected with HIV-1 and bacteria showed decreased cell viability, increased bacilli proliferation and altered cytokine production in vitro [42]. Additionally, phagocytosis of Mtb by macrophages can enhance transcription of HIV in vitro [50]. To further complicate matters, HIV-1/Mtb co-infection also affects TB diagnosis. People infected with both Mtb and HIV-1 are likely to be sputum negative. Since the presence of TB-positive sputum is the primary clinical manifestation of TB, TB in HIV-1 infected individuals is often difficult to diagnose. 
Table 1: Absolute peripheral blood counts $\left(\right.$ cells $/ \mathrm{mm}^{3}$ ) showing the pronounced CD4 ${ }^{+}$and $\mathrm{CD}^{+}$ T-cell deficit in co-infected individuals as compared to those with only HIV or TB [46].

\begin{tabular}{lccc}
\hline T-cell Count & CD4 $^{+}$ & CD8 $^{+}$ & \\
\hline Healthy & 1153 & 670 & Median \\
& $715-2218$ & $340-1800$ & Range \\
TB only & 690 & 355 & Median \\
& $291-1124$ & $138-917$ & Range \\
HIV only & 178 & 517 & Median \\
& $38-262$ & $438-1108$ & Range \\
HIV \& TB & 53.5 & 196 & Median \\
& $2-194$ & $10-1009$ & Range \\
\hline
\end{tabular}

\section{Methods}

\subsection{Model Development}

To help us understand the role of HIV-1 infection on the reactivation of latent TB, we develop a mathematical model that describes the time course of the adaptive immune response to co-infection with HIV-1 and Mtb. We choose to model the dynamics of immune cells and pathogens in the lung as this is the primary site of infection for Mtb and there is evidence that the lungs are an important site for HIV-1 infection due to its highly vascular structure [45]. There is also evidence in non-human primate models of SIV infection indicating that HIV-1 is present there [19]. Further, mechanisms driving TB reactivation likely occur in the lung. Although the lymph nodes are the site of the generation of the adaptive response, we allow that compartment to be captured phenomenologically as a first step. Previously, Kirschner developed a simple model of TB/HIV-1 co-infection dynamics [28]. That work showed that HIV-1/Mtb co-infection results in lower T-cell levels, and greater bacterial or viral loads than those seen during Mtb only or HIV-1 only infections respectively. That study also predicted that co-infection induced the reactivation of latent TB in almost every case. In this work, we include many more mechanistic details about the immune system response, such as the role of key cytokines, and the interactions between different T-cell and macrophage populations. By incorporating these additional dynamics, we hope to contribute further to the understanding of HIV-1 induced TB.

The model we develop captures the dynamics occurring between macrophages, various subpopulations of T-cells, bacteria, virus, and select cytokines using 19 nonlinear, ordinary differential equations. We base our ideas on previous research performed by our group [35][36][37][55][8][27] and further develop these models to incorporate the effects of co-infection. We include five different subpopulations of macrophages: resting $\left(M_{r}\right)$, activated $\left(M_{a}\right)$, HIV-1 infected $\left(M_{V}\right)$, Mtb infected $\left(M_{M}\right)$, and co-infected macrophages $\left(M_{C}\right)$ that dynamically interact with six subpopulations of 
T-cells: resting CD4 ${ }^{+}\left(T_{4}\right)$, Th1 $\left(T_{1}\right), \mathrm{HIV}-1$ infected CD4 ${ }^{+}\left(T_{V}\right)$, resting CD8 ${ }^{+}\left(T_{8}\right), \mathrm{HIV}-1$ specific cytotoxic $\left(K_{V}\right)$, and Mtb specific cytotoxic T lymphocytes $\left(K_{M}\right)$. In addition, we incorporate intracellular $\left(B_{i}\right)$ and extracellular $\left(B_{e}\right)$ Mtb, HIV-1 particles $(V)$, and several cytokines critical to Mtb and HIV-1 infection: TNF- $\alpha(F), \operatorname{IFN}-\gamma\left(I_{\gamma}\right)$, IL-10 $\left(I_{10}\right), \operatorname{IL}-12\left(I_{12}\right)$ and IL-4 $\left(I_{4}\right)$. Parameter values used in our model for numerical simulations are given in Tables 2-4 in Appendix A.1.

\subsubsection{The Role of Macrophages During Infection}

The rate of change of resting macrophages is described mathematically by Eqn. 2.1. This equation includes a constant source (term 1) and natural death term (term 7) maintaining a homeostatic level of resting macrophages that would typically be present in a healthy immune system. During infection, resting macrophages are recruited to the site of infection in response to TNF [5], a process that is inhibited by IL-10 (term 5) [14], and are additionally recruited by chemokines produced by activated and infected macrophages (term 2) [5]. Term 6 accounts for the fact that in the presence of IFN $-\gamma$, macrophage activation occurs given a secondary signal from TNF or extracellular bacteria [18]. Resting macrophages may become infected by either free Mtb or HIV-1 and this is captured in terms 3 and 4 . The rate that resting macrophages become infected by Mtb depends on the number of resting macrophages and the amount of extracellular bacteria present. As shown in Eqn. 2.4, Mtb infected macrophages can be cleared either by bursting (term 3), which occurs when the macrophage reaches its intracellular bacterial carrying capacity, lysis by killer T-cells (term 4), apoptosis induced by either T helper cells (Fas-FasL) (term 5) or TNF (term 6), or they can die naturally (term 7). Eqn. 2.3 represents that macrophages that become infected with HIV-1 $\left(M_{V}\right)$ undergo apoptosis induced by TNF (term 5), may be killed directly by HIV-1 specific CTLs (term 3), or may die naturally (term 6).

The first and second terms of Eqn. 2.5 capture the increase in the co-infected macrophage population when Mtb infected macrophages become infected with HIV-1 and vice versa. Co-infected macrophages exhibit prolonged and increased production of TNF, increased Mtb production (but not HIV-1 production) (term 6 in Eqn. 2.12), and increased cell death (term 7). Co-infected macrophages can be cleared either by bursting (term 3), by Fas-FasL or TNF-induced apoptosis (term 5) [26], lysis by helper and killer T-cells (terms 4 and 6), or they can die naturally at a rate $\mu_{M_{C}}$.

The equations governing the dynamics of resting $\left(M_{r}\right)$, activated $\left(M_{a}\right)$, HIV-1 infected $\left(M_{V}\right)$, Mtb infected $\left(M_{M}\right)$, and co-infected macrophages $\left(M_{C}\right)$ respectively are as follows.

$$
\begin{aligned}
& \frac{d M_{r}}{d t}=s_{M_{r}}+\alpha_{4 A}\left[M_{a}+w_{2}\left(M_{M}+M_{C}+M_{V}\right)\right]-k_{2 M} M_{r}\left(\frac{B_{e}}{B_{e}+c_{9}}\right)-k_{2 V} M_{r} V \\
& \quad+s r_{4 B}\left(\frac{F}{F+f_{8} I_{10}+s_{4 b}}\right)-k_{3} M_{r}\left(\frac{I_{\gamma}}{I_{\gamma}+f_{1} I_{4}+s_{1}}\right)\left(\frac{B_{T}+\beta_{1} F}{B_{T}+\beta_{1} F+c_{8}}\right)-\mu_{M_{r}} M_{r}
\end{aligned}
$$




$$
\begin{aligned}
& \frac{d M_{a}}{d t}=k_{3} M_{r}\left(\frac{I_{\gamma}}{I_{\gamma}+s_{1}}\right)\left(\frac{B_{T}+\beta_{1} F}{B_{T}+\beta_{1} F+c_{8}}\right)-k_{2 V} M_{a} V \\
& -k_{4} M_{a}\left(\frac{I_{10}}{I_{10}+s_{8}}\right)-\mu_{M_{a}} M_{a} \\
& \begin{array}{r}
\frac{d M_{V}}{d t}=k_{2 V} M_{r} V+k_{2 V} M_{a} V-k_{52_{V}} M_{V}\left[\frac{\left(K_{V}\left(\frac{T_{1}}{T_{1}+c_{T_{1}}}\right)+w_{1} T_{1}\right) / M_{V}}{\left(K_{V}\left(\frac{T_{1}}{T_{1}+c_{T_{1}}}\right)+w_{1} T_{1}\right) / M_{V}+c_{52_{V}}}\right] \\
-k_{V M} M_{V}\left(\frac{B_{e}}{B_{e}+c_{9}}\right)-k_{14 B} M_{V}\left(\frac{F}{F+f_{9} I_{10}+s_{4 b}}\right)-\mu_{M_{V}} M_{V}
\end{array}
\end{aligned}
$$

$$
\begin{array}{r}
\frac{d M_{M}}{d t}=k_{2 M} M_{r}\left(\frac{B_{e}}{B_{e}+c_{9}}\right)-k_{M V} M_{M} V-k_{17} M_{M}\left(\frac{B_{i}^{2}}{B_{i}^{2}+\left(N M_{M}\right)^{2}}\right) \\
-k_{14 A} M_{M}\left[\frac{\left(K_{M}+w_{3} T_{1}\right) / M_{M}}{\left(K_{M}+w_{3} T_{1}\right) / M_{M}+c_{4}}\right]-k_{14 B} M_{M}\left(\frac{F}{F+f_{9} I_{10}+s_{4 b}}\right) \\
-k_{52_{M}} M_{M}\left[\frac{\left(K_{M}\left(\frac{T_{1}}{T_{1}+c_{T_{1}}}\right)+w_{1} T_{1}\right) / M_{M}}{\left(K_{M}\left(\frac{T_{1}}{T_{1}+c_{T_{1}}}\right)+w_{1} T_{1}\right) / M_{M}+c_{52_{M}}}\right]-\mu_{M_{M} M_{M}}
\end{array}
$$

$$
\begin{aligned}
& \frac{d M_{C}}{d t}=k_{V M} M_{V}\left(\frac{B_{e}}{B_{e}+c_{q}}\right)+k_{M V} M_{M} V-k_{17}\left(\frac{V}{V+\hat{k}_{17}}\right) M_{C}\left(\frac{B_{i}^{2}}{B_{i}^{2}+\left(N M_{C}\right)^{2}}\right) \\
& -k_{52_{M}} M_{C}\left[\frac{\left(K_{M}\left(\frac{T_{1}}{T_{1}+c_{T_{1}}}\right)+w_{1} T_{1}\right) / M_{C}}{\left(K_{M}\left(\frac{T_{1}}{T_{1}+c_{T_{1}}}\right)+w_{1} T_{1}\right) / M_{C}+c_{52_{M}}}\right]-k_{14 B} M_{C}\left(\frac{F}{F+f_{9} I_{10}+s_{4 b}}\right) \\
& -k_{52_{V}} M_{C}\left[\frac{\left(K_{V}\left(\frac{T_{1}}{T_{1}+c_{T_{1}}}\right)+w_{1} T_{1}\right) / M_{C}}{\left(K_{V}\left(\frac{T_{1}}{T_{1}+c_{T_{1}}}\right)+w_{1} T_{1}\right) / M_{C}+c_{52_{V}}}\right]-\mu_{M_{C}} M_{C}
\end{aligned}
$$

\subsubsection{T-Cell Response}

Eqn. 2.7 describes the time evolution of resting CD4 ${ }^{+}$T-cells. Since the trafficking of immune cells to the lung from the lymph node is not explicitly modeled, a source of resting CD4 ${ }^{+}$T-cells is included that depends on the number of infected and activated macrophages (term 1). Resting $\mathrm{CD} 4^{+}$T-cells will proliferate in response to signals from helper T-cells and activated macrophages (term 2), and, as described in the third term, be recruited to the site of infection in response to TNF [5]. $\mathrm{CD}^{+}{ }^{+}$T-cell proliferation is diminished due to HIV-1 infection (third factor in term 2) [44]. Resting CD4 ${ }^{+}$T-cells become infected by HIV-1 either through interactions with infected macrophages (term 4) or with free virus (term 5). The rate at which resting $\mathrm{CD}^{+}{ }^{+} \mathrm{T}$-cells become 
infected is inhibited by both IFN $-\gamma$ and killer T-cell secreted chemokines that compete with HIV-1 for binding to the CCR5 receptor or CXCR4 HIV coreceptors [22] on the CD4 ${ }^{+}$T-cell. Infected $\mathrm{CD}^{+}$cells can be destroyed by CTL killing or they can die naturally. Infected T-cells produce an increased amount of TNF. Resting CD4 $4^{+}$T-cells become activated by IL-12 and interaction with antigen presenting cells (term 6). The last term captures the natural death of these T-cells.

Helper T-cell trafficking from the lymph node is captured with a source term dependent on the level of infection and activated macrophages, but additional recruitment occurs in response to TNF. The rate of change of Th1 helper T-cells also increases as resting $\mathrm{CD}^{+}{ }^{+} \mathrm{T}$-cells become activated and Th1 polarized. Like resting CD4 ${ }^{+}$T-cells, helper T-cells can become infected by HIV-1 and die naturally. In the presence of activated macrophages, Th1 T-cells can be killed by IFN- $\gamma$ induced apoptosis (term 6) [15].

Eqn. 2.9 represents the rate of change in $\mathrm{CD} 8^{+} \mathrm{T}$-cells. A source of $\mathrm{CD} 8^{+} \mathrm{T}-$ cells that is determined by the level of activated macrophages and infection (captured in first term). Similar to resting $\mathrm{CD}^{+}{ }^{+} \mathrm{T}$-cells, $\mathrm{CD} 8^{+} \mathrm{T}$-cells will proliferate in response to signals from activated macrophages (term 2) and be recruited to the site of infection in response to TNF (term 4). Additionally, CD8 ${ }^{+}$ T-cells can differentiate into either HIV-1 or Mtb specific CTLs and die naturally, as captured in terms 3,5 , and 6 respectively.

Eqns. 2.10 and 2.11 describe the HIV-1 and Mtb specific CTL population dynamics respectively. A small proportion of Mtb specific CTLs arrive at the site of infection from external sources and are modeled using a source term (term 1). Mtb specific CTLs are also recruited in response to TNF (term 2). Additional Mtb specific CTLs are generated when resting CD8 ${ }^{+} \mathrm{T}$-cells are activated and this process is augmented by IL-12 and IFN- $\gamma$ (term 3), but decreases in this population occur through IFN- $\gamma$ induced apoptosis (term 4) [47] and natural death (term 5). As shown in Eqn. 2.10, HIV-1 specific CTLs also arrive at the site of infection through external sources (term 1) and are generated by cross-presentation of an APC (represented by HIV-1 infected macrophages, $M_{V}$, in term 2) to the $T_{8}$.

The equations describing the dynamics of resting CD4 $4^{+}\left(T_{4}\right)$, Th1 $\left(T_{1}\right), \mathrm{HIV}-1$ infected CD4 ${ }^{+}$ $\left(T_{V}\right)$, resting $\mathrm{CD}^{+}\left(T_{8}\right), \mathrm{HIV}-1$ specific cytotoxic $\left(K_{V}\right)$, and Mtb specific cytotoxic T lymphocytes $\left(K_{M}\right)$ respectively are shown below.

$$
\begin{aligned}
\frac{d T_{4}}{d t}=\alpha_{1 A}\left[M_{a}+\right. & \left.w_{2}\left(M_{V}+M_{M}+M_{C}\right)\right]+\alpha_{2} T_{4}\left(\frac{M_{a}}{M_{a}+c_{15}}\right)\left(\frac{s_{v 3}}{s_{v 3}+V}\right) \\
& +s r_{1 B}\left(\frac{F}{F+f_{8} I_{10}+s_{4 b_{2}}}\right)-k_{V_{1}}\left(\frac{c_{V_{1}}}{K_{V}+c_{V_{1}}}\right) M_{V} T_{4} \\
& -k_{1} T_{4}\left(\frac{c_{1}}{K_{V}+c_{1}}\right) V-k_{6} I_{12} T_{4}\left(\frac{I_{\gamma}}{I_{\gamma}+f_{1} I_{4}+f_{7} I_{10}+s_{1}}\right)-\mu_{T_{4}} T_{4}
\end{aligned}
$$




$$
\begin{aligned}
\frac{d T_{1}}{d t}=\alpha_{3 A}\left[M_{a}+\right. & \left.w_{2}\left(M_{V}+M_{M}+M_{C}\right)\right]+s r_{3 B}\left(\frac{F}{F+f_{8} I_{10}+s_{4 b_{1}}}\right) \\
& -k_{V_{2}}\left(\frac{c_{V_{2}}}{K_{V}+c_{V_{2}}}\right) M_{V} T_{1}-k_{3 S} T_{1}\left(\frac{c_{3}}{K_{V}+c_{3}}\right) V \\
+ & k_{6} I_{12} T_{4}\left(\frac{I_{\gamma}}{I_{\gamma}+f_{1} I_{4}+f_{7} I_{10}+s_{1}}\right)-\mu_{T_{\gamma}} M_{a}\left(\frac{I_{\gamma}}{I_{\gamma}+c}\right) T_{1}-\mu_{T_{1}} T_{1}
\end{aligned}
$$

$$
\begin{array}{r}
\frac{d T_{V}}{d t}=k_{V_{1}}\left(\frac{c_{V_{1}}}{K_{V}+c_{V_{1}}}\right) M_{V} T_{4}+k_{V_{2}}\left(\frac{c_{V_{2}}}{K_{V}+c_{V_{2}}}\right) M_{V} T_{1} \\
\quad+k_{1} T_{4}\left(\frac{c_{1}}{K_{V}+c_{1}}\right) V+k_{3 S} T_{1}\left(\frac{c_{3}}{K_{V}+c_{3}}\right) V-\kappa K_{V} T_{V}-\mu_{T_{V}} T_{V}
\end{array}
$$

$$
\begin{aligned}
\frac{d T_{8}}{d t}=\alpha_{1 A}[ & \left.M_{a}+w_{2}\left(M_{V}+M_{M}+M_{C}\right)\right]+\alpha_{2} T_{8}\left(\frac{M_{a}}{M_{a}+c_{15}}\right)\left(\frac{s_{v 3}}{s_{v 3}+V}\right)-\chi_{T} T_{8} M_{V} \\
& +s r_{1 B}\left(\frac{F}{F+f_{8} I_{10}+s_{4 b_{2}}}\right)-k_{6} I_{12} T_{8}\left(\frac{I_{\gamma}}{I_{\gamma}+f_{1} I_{4}+f_{7} I_{10}+s_{1}}\right)-\mu_{T_{8}} T_{8}
\end{aligned}
$$

$$
\begin{aligned}
& \frac{d K_{V}}{d t}=\alpha_{3 A_{c}} w_{2}\left(M_{V}+M_{C}\right)+\chi_{T} T_{8} M_{V}-\mu_{c} K_{V} \\
& \begin{aligned}
\frac{d K_{M}}{d t}= & \alpha_{3 A_{c}}\left[M_{a}+w_{2}\left(M_{M}+M_{C}\right)\right]+s r_{3 B_{c}}\left(\frac{F}{F+f_{8} I_{10}+s_{4 b_{1}}}\right) \\
& +k_{6} I_{12} T_{8}\left(\frac{I_{\gamma}}{I_{\gamma}+f_{1} I_{4}+f_{7} I_{10}+s_{1}}\right)-\mu_{T_{c} \gamma} K_{M}\left(\frac{I_{\gamma}}{I_{\gamma}+c_{c}}\right) M_{a}-\mu_{T_{c}} K_{M}
\end{aligned}
\end{aligned}
$$

\subsubsection{Pathogen Dynamics}

Eqn. 2.12 describes the rate of change in extracellular Mtb. This population increases as a result of proliferation (term 1), infected macrophage bursting (terms 5-6) or natural death (term 2). Extracellular bacteria also increases as a result of Fas-FasL and TNF-induced macrophage apoptosis (terms 9-10). Extracellular bacteria can also be taken up by resting and activated macrophages (terms 3-4).

Eqn. 2.13 mathematically characterizes the rate of change in intracellular Mtb. Intracellular Mtb levels increase as macrophages become infected and the bacteria proliferate within these infected macrophages (terms 1-3). When an infected macrophage dies, whether it is by bursting (terms 4-5), Fas-FasL induced apoptosis (term 6) [53], or TNF-induced apoptosis (term 7) [11], a fraction of intracellular bacteria survive and become a source of extracellular Mtb. However, lysing by a CTL 
(terms 8-10) kills virtually all intracellular bacteria and does not contribute to the extracellular Mtb population [53].

The equations governing the growth and interactions of extracellular $\left(B_{e}\right)$ and intracellular $\left(B_{i}\right)$ Mtb respectively are as follows.

$$
\begin{aligned}
& \frac{d B_{e}}{d t}=\alpha_{20} B_{e}+\mu_{I} B_{i}-k_{15} M_{a} B_{e}-k_{18} M_{r} B_{e}+k_{17} N M_{M}\left(\frac{B_{i}^{2}}{B_{i}^{2}+\left(N M_{M}\right)^{2}}\right) \\
& +k_{17}\left(\frac{V}{V+\hat{k}_{17}}\right) N M_{C}\left(\frac{B_{i}^{2}}{B_{i}^{2}+\left(N M_{C}\right)^{2}}\right)-k_{2 M}\left(\frac{N}{2}\right) M_{r}\left(\frac{B_{e}}{B_{e}+c_{9}}\right) \\
& -k_{V M}\left(\frac{N}{2}\right) M_{V}\left(\frac{B_{e}}{B_{e}+c_{9}}\right)+k_{14 A} N N_{\mathrm{frac}_{\mathrm{c}}} M_{M}\left[\frac{\left(K_{M}+w_{3} T_{1}\right) / M_{M}}{\left(K_{M}+w_{3} T_{1}\right) / M_{M}+c_{4}}\right] \\
& +k_{14 B} N N_{\mathrm{frac}_{\mathrm{a}}} M_{M}\left(\frac{F}{F+f_{9} I_{10}+s_{4 b}}\right) \\
& \frac{d B_{i}}{d t}=\alpha_{19} B_{i}\left(1-\frac{B_{i}^{2}}{B_{i}^{2}+\left(N M_{M}\right)^{2}}\right)+k_{2 M}\left(\frac{N}{2}\right) M_{r}\left(\frac{B_{e}}{B_{e}+c_{9}}\right) \\
& +k_{V M}\left(\frac{N}{2}\right) M_{V}\left(\frac{B_{e}}{B_{e}+c_{9}}\right)-k_{17} N M_{M}\left(\frac{B_{i}^{2}}{B_{i}^{2}+\left(N M_{M}\right)^{2}}\right) \\
& -k_{17}\left(\frac{V}{V+\hat{k}_{17}}\right) N M_{C}\left(\frac{B_{i}^{2}}{B_{i}^{2}+\left(N M_{C}\right)^{2}}\right)-k_{14 A} N M_{M}\left[\frac{\left(K_{M}+w_{3} T_{1}\right) / M_{M}}{\left(K_{M}+w_{3} T_{1}\right) / M_{M}+c_{4}}\right] \\
& -k_{14 B} N M_{M}\left(\frac{F}{F+f_{9} I_{10}+s_{4 b}}\right)-k_{52_{M}} N M_{M}\left[\frac{\left(K_{M}\left(\frac{T_{1}}{T_{1}+c_{T_{1}}}\right)+w_{1} T_{1}\right) / M_{M}}{\left(K_{M}\left(\frac{T_{1}}{T_{1}+c_{T_{1}}}\right)+w_{1} T_{1}\right) / M_{M}+c_{52_{M}}}\right] \\
& -k_{52_{M}} N M_{C}\left[\frac{\left(K_{M}\left(\frac{T_{1}}{T_{1}+c_{T_{1}}}\right)+w_{1} T_{1}\right) / M_{C}}{\left(K_{M}\left(\frac{T_{1}}{T_{1}+c_{T_{1}}}\right)+w_{1} T_{1}\right) / M_{C}+c_{52_{M}}}\right] \\
& -k_{52_{V}} N M_{C}\left[\frac{\left(K_{V}\left(\frac{T_{1}}{T_{1}+c_{T_{1}}}\right)+w_{1} T_{1}\right) / M_{C}}{\left(K_{V}\left(\frac{T_{1}}{T_{1}+c_{T_{1}}}\right)+w_{1} T_{1}\right) / M_{C}+c_{52_{V}}}\right]-\mu_{I} B_{i}
\end{aligned}
$$

HIV-1 virions (V) are generated within productively infected T-cells (first term in Eqn. 2.14) and infected macrophages (terms 2,3). We also account for the fact that HIV-1 specific CTLs inhibit the production of new virus as well as natural virion death (term 4). Virion production occurs at such a rapid rate that we neglect other terms, such as viral uptake by immune cells.

The equation describing the production of HIV-1 is given by

$$
\frac{d V}{d t}=N_{V} T_{V}\left(\frac{c_{5}}{K_{V}+c_{5}}\right) \mu_{T_{V}}+\Pi_{M} M_{V}+\Pi_{M} M_{C}-\mu_{V} V .
$$




\subsubsection{Effects of Cytokine Production}

Eqn. 2.15 shows the time evolution of TNF. TNF is mainly secreted by infected macrophages (term 1), however, activated macrophages will also produce TNF in response to IFN- $\gamma$ or total Mtb (term 2). TNF is additionally produced by helper and killer T-cells (terms 3, 4 respectively), and has a natural half-life (term 5).

Eqn. 2.16 describes the rate of change of IFN- $\gamma$ in time. IFN- $\gamma$ is produced by infected macrophages (term 3 of Eqn. 2.16), Th1 (term1) and killer (term 2) T-cells in response to activated macrophages [31], and has a natural half-life. An additional source term (term 4) is included to capture the production of IFN- $\gamma$ by natural killer cells that depends on the bacterial load and IL-12 concentration [29].

IL-10 is primarily produced by activated macrophages, a process that is inhibited by IL-10 and IFN $-\gamma$ [24]. This is described mathematically by the first term of Eqn. 2.17 It is additionally produced by helper and killer T-cells (terms 2, 3 respectively) and has a natural half-life (term 4). IL-10 inhibits synthesis of pro-inflammatory cytokines like IFN- $\gamma$, IL-2, and TNF.

$\mathrm{IL}-12$ is produced by both resting and activated macrophages [24] as shown in the first and second terms of Eqn. 2.18. However, during Mtb infection, dendritic cells are actually the primary source of IL-12 [24]. Since dendritic cells are not explicitly being modeled, the third term is a source term that captures this dynamic. On the other hand, a decrease in IL-12 secretion during HIV-1 infection has been proposed as a major defect in the ability to control HIV-1 and other opportunistic infections otherwise cleared by cell-mediated responses. Here we allow for the possibility that viral load reduces IL-12 production (term 3). The final term in Eqn. 2.18 indicates that IL-12 is also naturally degraded.

IL-4 production by resting CD4 ${ }^{+}$T-cells is included to account for its inhibitory effect on IFN- $\gamma$ induced macrophage activation and resting T-cell differentiation (first term of Eqn. 2.19). The second term accounts for the fact that IL-4 is also naturally degraded.

The equations describing TNF- $\alpha(F)$, IFN- $\gamma\left(I_{\gamma}\right)$, IL-10 $\left(I_{10}\right)$, IL-12 $\left(I_{12}\right)$ and IL-4 $\left(I_{4}\right)$ production and half-life decay are given by

$$
\begin{aligned}
\frac{d F}{d t}=\alpha_{30}\left(M_{M}+M_{V}+M_{C}\right)+\alpha_{31} & M_{a}\left(\frac{I_{\gamma}+\beta_{2} B_{T}}{I_{\gamma}+\beta_{2} B_{T}+f_{1} I_{4}+f_{7} I_{10}+s_{10}}\right) \\
& +\alpha_{32} T_{1}\left(\frac{V}{V+s_{v_{3}}}\right)+\alpha_{33}\left(K_{M}+K_{V}\right)-\mu_{F} F
\end{aligned}
$$




$$
\begin{array}{r}
\frac{d I_{\gamma}}{d t}=+\alpha_{5 A} T_{1}\left(\frac{M_{a}}{M_{a}+c_{5 A}}\right)\left(\frac{s_{v_{2}}}{s_{v_{2}}+V}\right)+\alpha_{5 B}\left(K_{M}+K_{V}\right)\left(\frac{M_{a}}{M_{a}+c_{5 B}}\right) \\
+\alpha_{5 C}\left(M_{M}+M_{V}+M_{C}\right)+s_{\gamma}\left(\frac{B_{T}}{B_{T}+c_{10}}\right)\left(\frac{I_{12}}{I_{12}+s_{7}}\right)-\mu_{\gamma} I_{\gamma}
\end{array}
$$

$$
\frac{d I_{10}}{d t}=\delta_{6} M_{a}\left(\frac{s_{6}}{I_{10}+f_{6} I_{\gamma}+s_{6}}\right)+\alpha_{16} T_{1}\left(\frac{s_{v_{1}}}{s_{v_{1}}+V}\right)+\alpha_{18}\left(K_{V}+K_{M}\right)-\mu_{i 10} I_{10}
$$

$$
\begin{aligned}
\frac{d I_{12}}{d t}=\alpha_{23} M_{r}\left(\frac{B_{T}}{B_{T}+c_{23}}\right)\left(\frac{s_{v}}{s_{v}+V}\right)+ & \alpha_{8} M_{a}\left(\frac{s}{s+I_{10}}\right)\left(\frac{s_{v}}{s_{v}+V}\right) \\
& +s_{12}\left(\frac{B_{T}}{B_{T}+c_{230}}\right)\left(\frac{V}{V+\phi_{L}}\right)-\mu_{i 12} I_{12}
\end{aligned}
$$

$$
\frac{d I_{4}}{d t}=\alpha_{11} T_{4}-\mu_{i 4} I_{4}
$$

\subsection{Uncertainty and Sensitivity Analysis}

Whenever possible, we use experimental data to determine the model parameter values. However, variability and uncertainty inherently exist due to imprecision in experimental measurement, differences among host populations, and differences in experimental design (e.g., in vitro vs. in vivo). To determine the sensitivity of our results to the parameter values chosen, we perform a samplebased sensitivity analysis that combines Latin hypercube sampling (LHS) of the parameter space and partial rank correlation coefficients (PRCCs). For each input parameter, LHS technique generates $N$ samples from probability distributions (i.e., probability density functions) assigned a priori to each parameter, where $N$ denotes the number of simulations required for a reliable analysis. No rule exists as to what the optimal sample size should be to perform a reliable analysis: usually $N$ is set to 500 or 1000 for accuracy, unless the computational cost is prohibitive. Each interval is then divided into $N$ equiprobable subintervals to be sampled without replacement. Sampling is conducted independently for each parameter and a matrix (LHS matrix) of $N$ rows and $k$ columns (e.g., the number of parameters included in the analysis) is generated. Each row represents a parameter combination that is fed into the model: $N$ outputs are generated and PRCCs are calculated between LHS matrix and the output vector. The partial rank correlation coefficient is a measure of the strength of the relationship between each input variable and each output variable, after the effects of other parameters have been discounted. Results of the PRCC are dependent on the choice of parameter ranges used in LHS. For a complete study of uncertainty and sensitivity analysis as it applies to mathematical modeling of biological systems, see [38].

In our analysis of this co-infected system, we use total bacterial load $\left(B_{T}=B_{e}+B_{i}\right)$ as an indicator of Mtb infection. To measure the progression of HIV-1 infection, we use viral titer $(V)$ 
and total CD4 count $\left(T_{4}+T_{1}+T_{V}\right)$. We select all three outputs $\left(B_{T}, V, T_{4}+T_{1}+T_{V}\right)$ for the uncertainty and sensitivity analysis of the co-infection scenario. We set $N=1000$ for the LHS and specify uniform probability density functions for each parameter variability. We study 27 TB related parameters in the TB only LHS-PRCC analysis (see Table 4 in the Appendix for details). For HIV only and the co-infection scenario, we conduct uncertainty and sensitivity analysis by varying only HIV related parameters (see Table 3 in the Appendix for details). We select a subset of 29 parameters for the co-infection scenario, assuming that all TB related parameters are unchanged and set to the values used to control and mantain TB. In other words, HIV-1 infection does not directly alter TB related parameters.

\section{Results}

To verify that the model is working and gives biologically reasonable results, we perform a series of negative and positive control experiments to compare with previously studied cases. Each of these models yields results for population cell sizes in the lung (number of cells per $\mathrm{mm}^{3}$ ) and cytokines in $\mathrm{pg} / \mathrm{ml}$. Three control experiments were performed: 1 ) negative control where the individual is healthy, that is, there is no Mtb or HIV-1 and there is a constant level $\left(3 \times 10^{5}\right.$ per $\left.\mathrm{mm}^{3}\right)$ of resting macrophages, 2) Mtb infection, which is a healthy person who has inhaled 40 bacteria, and 3) HIV-1 infection, which is a healthy host who becomes infected with HIV-1. In the absence of any infection, resting macrophage levels remain constant and all other variables are zero (not shown). Results from cases 2 and 3 are presented below. Table 5 summarizes the initial conditions used for each scenario. We would like to point out that parameter values used in this model are taken from the literature, but they are derived from many different experimental systems and species. Consequently, the biological variability between animal models introduces an inherent degree of uncertainty in parameter estimates. We address this uncertainty systematically using the sensitivity analysis techniques described in section 2.2. A list of parameter definitions and their values are given in the Appendix.

\subsection{Mtb Infection Without HIV-1 Present}

Figure 2 shows one outcome of a healthy host infected with Mtb. After approximately 120 days (4 months), extracellular bacteria levels are controlled and the host enters latent infection. Each infected macrophage carries approximately 10 bacteria (computed from number of infected macrophages divided by the number of intracellular bacteria in steady state). Cellular and cytokine level dynamics agree with those obtained previously [58][55][37]. Our simulations show that Mtb infection can also result in active TB disease (Fig. 3). For example, changing the parameters $k_{14 A}$, $k_{15}, \alpha_{20}, N$, and $k_{17}$ and holding all other parameters in Tables 2-4 fixed, the system progresses to active disease instead of latency. In the sections following, we discuss how to determine which parameters in the model can control this type of bifurcation. During active TB, we observe growing intracellular and extracellular bacterial levels, and, compared to latent infection, a heightened immune response evidenced by significantly greater activated and infected macrophage and T-cell 
numbers and cytokine levels. These two results compare qualitatively and quantitatively well with the latent and active TB results published previously [55]. As seen in Figure 3, after 200 days the extracellular bacteria burden increases to levels that are no longer biologically relevant as the host would die of bacterial sepsis given bacterial loads this high. Accordingly, we limit our interpretation and comparisons of immune response dynamics to 200 days.
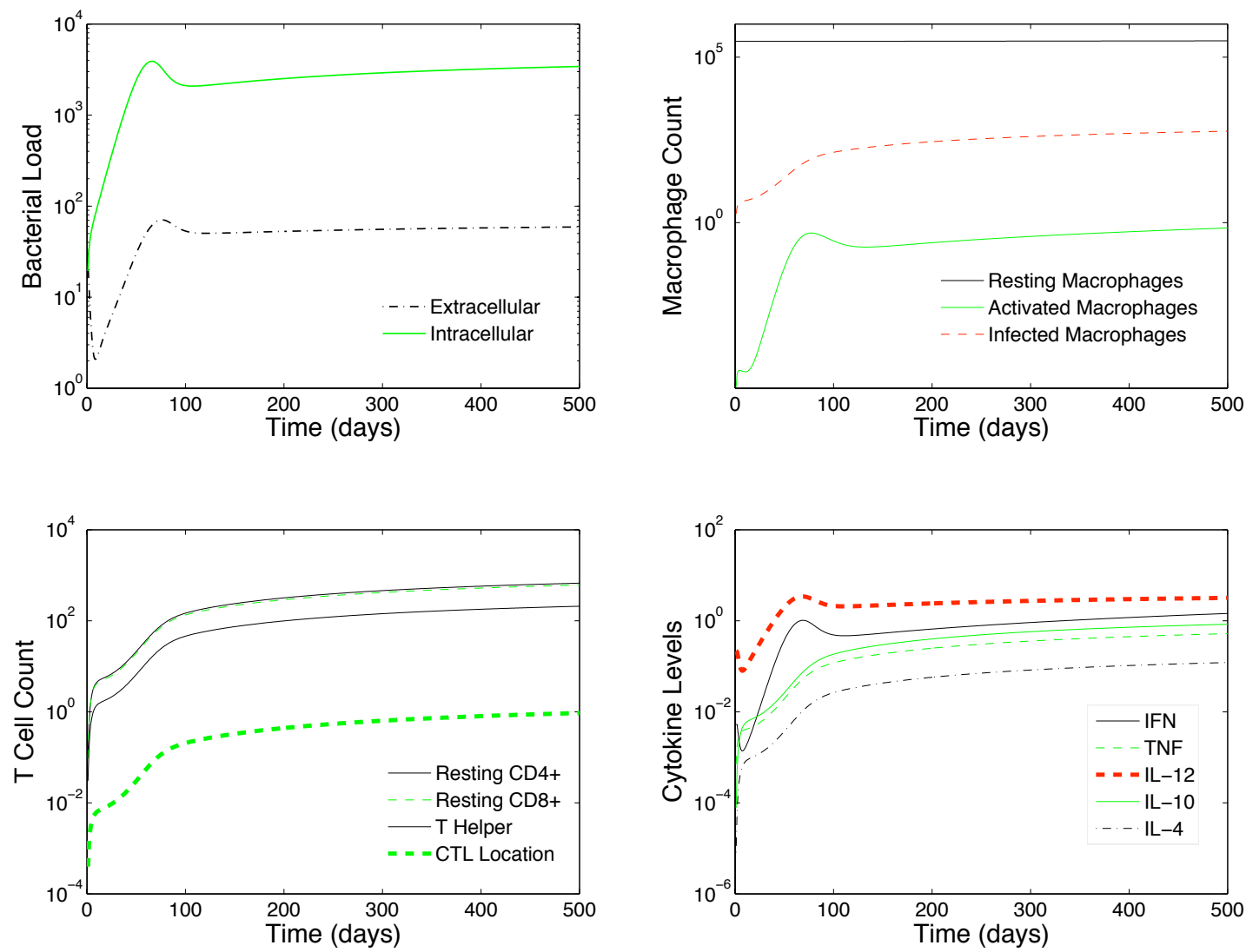

Figure 2: Numerical simulation of an initially healthy host infected with Mtb. Host shows containment of infection and enters latency after approximately 120 days (4 months). These simulations agree with those published in [55]. Parameter set shown in Tables 2-4. Units are measured in cells $/ \mathrm{mm}^{3}$ and $\mathrm{pg} / \mathrm{ml}$ for cytokine concentrations.

\subsubsection{Identifying Parameters that Govern Mtb Infection Dynamics}

For Mtb infection alone, numerically there are 3 steady states: clearance (not shown), latency (Fig. 2), and active disease (Fig. 3). To identify which parameters in the model regulate switching 

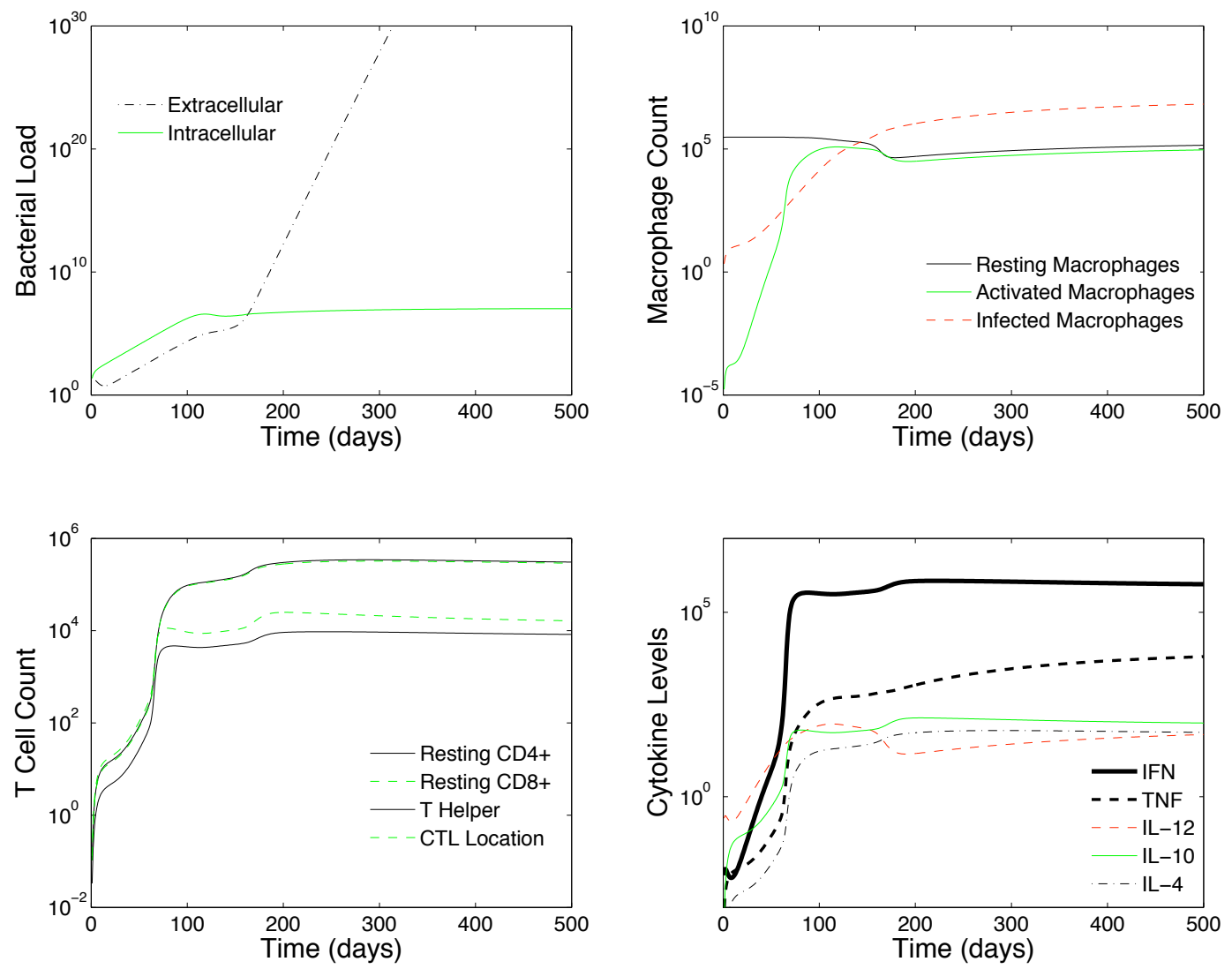

Figure 3: Numerical simulation of an initially healthy host infected with Mtb that results in active Mtb infection. Extracellular bacterial loads increase and the host progresses to active TB. These results agree with those published in [55][37]. The parameters that are different from those used to obtain the latency results depicted in Figure 2 are $k_{14 A}, k_{15}, \alpha_{20}, N$ and $k_{17}$. Units are measured in cells $/ \mathrm{mm}^{3}$ and $\mathrm{pg} / \mathrm{ml}$ for cytokine concentrations. 
between these steady states (i.e., bifurcation-type parameters) we employ the sensitivity analysis as described in section 2.2. This analysis identifies several mechanisms that regulate Mtb infection outcome (see Table 6 ). The rate of bursting of infected macrophages $\left(k_{17}\right)$ is negatively correlated with bacterial load, while extracellular bacteria growth rate $\left(\alpha_{20}\right)$ and the half saturation of bacterial infection rate of macrophages $\left(c_{9}\right)$ are both positively correlated with total bacterial levels. Interestingly, the parameter $N$, which represents the carrying capacity of infected macrophages is negatively correlated with total bacterial load. In addition, the rate that macrophages become infected with $\mathrm{Mtb}\left(k_{2 M}\right)$ is also negatively correlated with infection outcome throughout infection. This finding suggests that as more macrophages become infected, more bacteria are trapped inside macrophages, and therefore the chance they can be killed from cytotoxic or apoptotic mechanisms, or after being released due to $M_{M}$ bursting, is higher. This dynamic ultimately has a negative impact on bacterial levels.

\subsection{HIV-1 Infection Only}

Figure 4 shows the simulated dynamics of cytokines, virus, and cell population in the lung of a HIV-1 infected person. Infection is initiated by the arrival of 10 virions at time zero. Infected cells (T-cells and macrophages) rapidly increase, free virus rapidly increases, and total cell populations increase due to recruitment and proliferation in response to infection in the lung. After approximately 2 months, the system reaches a steady state of infection consistent with the establishment of a clinical set-point viral load and immune activation level [25]. Relatively little experimental data exists for HIV-1 dynamics in the lung. However, we find that this model qualitatively recapitulates the increase in infected cell counts seen between 2 weeks post-infection and 1-2 months postinfection in a rhesus macaque simian immunodeficiency virus infection model [19]. Moreover, this animal study finds that on average, at 1-2 months post-infection, 85.9 percent of virus-infected cells are $\mathrm{CD}^{+} 8^{+}$, a marker for macrophages. Our model quantitatively recapitulates this finding, as 90 percent of infected cells in our simulation are macrophages at day 500 of infection (Fig. 4).

\subsubsection{Identifying Parameters that Govern HIV-1 Infection Dynamics}

Performing sensitivity and uncertainty analysis on the system when only HIV-1 infection is present, we find that many of the same mechanisms that significantly affect viral load $(V)$ also significantly affect total $\mathrm{CD}^{+}{ }^{+} \mathrm{T}$-cell counts $\left(T_{4}+T_{1}+T_{V}\right)$ (see Table 7). The effects of these parameters are consistent throughout the entire course of infection. The parameter $\mu_{M_{V}}$ (virus-infected macrophage natural death rate) is negatively correlated with both viral load and total $\mathrm{CD} 4^{+}$counts. Virus death rate $\mu_{V}$ is also negatively correlated to viral load. Other parameters positively correlated to viral load and $\mathrm{CD}_{4}^{+}$count include: $c_{52_{V}}$, the half-saturation rate for CTL killing of infected macrophages; $k_{2 V}$, the macrophage infection rate; and, $\Pi_{M}$, the infected macrophage virus production rate. That these parameters all significantly affect both viral load and total CD4 ${ }^{+} \mathrm{T}$-cell count, with the same correlation coefficient sign, is surprising: in other physiological compartments, such as blood and lymphoid tissue, higher viral loads are associated with $\mathrm{CD} 4^{+} \mathrm{T}-$ cell depletion. This $\mathrm{CD}^{+} \mathrm{T}$-cell depletion is often attributed to failure of homeostatic mechanisms in the bone marrow, 
thymus, or lymphoid tissue - a phenomenon that this lung infection model cannot capture. Therefore, this finding is consistent with the idea that T-cells are increasingly recruited to, and infected, in peripheral sites of infection like the lung, despite a failure to replenish them elsewhere in the body. Indeed, we find that parameter $\alpha_{30}$, recruitment of T-cells by macrophage-produced TNF, is the parameter most strongly correlated with total $\mathrm{CD} 4^{+}$counts.
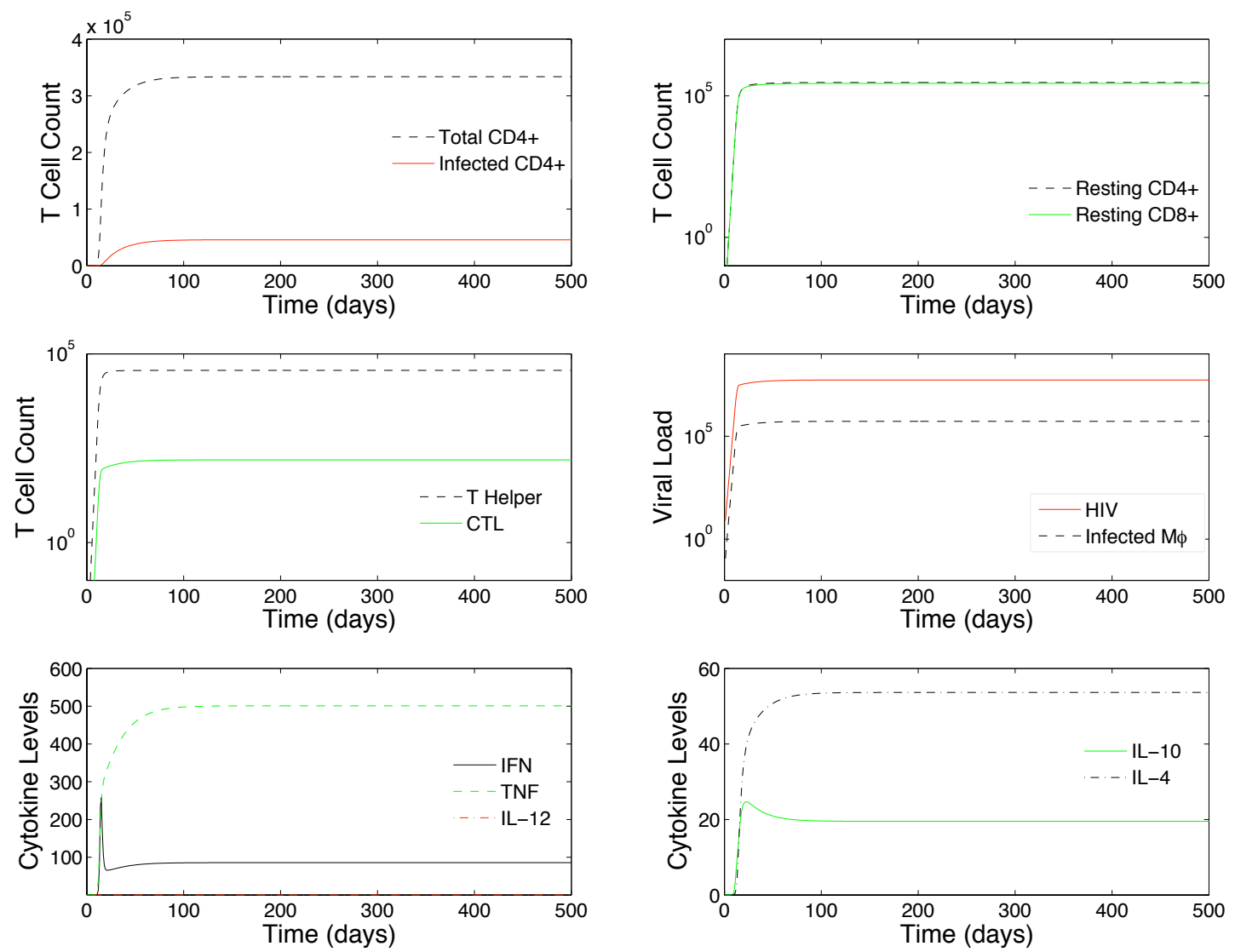

Figure 4: Numerical simulation of HIV-1 infection over 500 days in the lung during acute disease. Parameters are given in Tables 2-4. The host rapidly becomes infected with HIV-1 and in response immune cell counts increase. Units are measured in cells $/ \mathrm{mm}^{3}$ and $\mathrm{pg} / \mathrm{ml}$ for cytokine concentrations.

\subsection{HIV-1/Mtb Co-Infection}

Since two billion people in the world are latently infected with TB, our goal is to understand how HIV-1 infection impacts that latent infection. Using the results from the latent Mtb infection as 
initial conditions (see Table 5 and Fig. 2), we simulate TB/HIV-1 co-infection by infecting a latent TB host with HIV-1. Figure 5 shows the HIV-1 infection of a host with latent TB over 30 days and captures the very early dynamics of HIV-1/Mtb co-infection. Within the first week, there is a decrease in both intracellular and extracellular bacterial loads coincident with the increase in the number of activated macrophages that results from greater levels of IFN $-\gamma$. In addition, during this time $\mathrm{CD} 4^{+} \mathrm{T}$-cells and CTLs are recruited to the site of infection. $\mathrm{CD} 4^{+} \mathrm{T}$-cells and activated macrophages quickly become infected with HIV-1 and viral load rises. Figure 6 shows the immune system dynamics of HIV-1/Mtb co-infection over the course of 500 days ( $>1$ year). We observe that, in the presence of HIV-1 co-infection, a host with latent TB is now unable to control bacterial growth. Intracellular and extracellular bacterial burdens increase and the immune response fails to contain the Mtb infection. Viral infection is also sustained. After an initial increase, both $\mathrm{CD}^{+}$ and $\mathrm{CD} 8^{+} \mathrm{T}$-cells decline. Viral load initially increases and is then followed by a lower set-point. This decline in T-cells, which is not observed in the TB infection (see Figs. 2 and 3), is likely due to a completely different cytokine environment that impacts recruitment and $\mathrm{CD} 4^{+} \mathrm{T}$-cell profile (see below for details). Comparing HIV-1 infection dynamics (Fig. 4) with active TB (Fig. 3), we notice that $\mathrm{CD}^{+}{ }^{+} \mathrm{T}$-cell levels are lower in HIV-1 infection than those present during Mtb infection and that $\mathrm{CD}^{+}{ }^{+}$-cell counts are at similar levels during HIV-1 and Mtb only infections. These findings are qualitatively verified by the empirical results presented in Table 1 of section 1.4. Of course this assumes that the relative T-cell count in the blood is representative of the relative Tcell count in the lung. When we compare the immune system response to HIV-1/Mtb co-infection (Fig. 6) to the immune response of a host infected with either Mtb or HIV-1 (Figs. 3 and 4), several key differences can be seen. A co-infected host has lower resting $\mathrm{CD}^{+}{ }^{+}$and $\mathrm{CD} 8^{+} \mathrm{T}$-cell counts than in HIV-1 infection or Mtb infection alone. These results also compare qualitatively well with those presented in Table 1. Interestingly, while we do not observe a decrease in CD8 ${ }^{+}$T-cells and CTL cells in a host infected with either HIV-1 or Mtb, we observe that these cells are depleted over time in a co-infected host.

This model captures some key dynamics that are observed during HIV-1/Mtb co-infection, including the reactivation of latent $\mathrm{TB}$ and rapid progression to active disease, and lower $\mathrm{CD}^{+}$and $\mathrm{CD}^{+} \mathrm{T}$-cell levels than in singly infected individuals (see Table 1 for experimental data on T-cell counts). Comparing the dynamics of viral loads during HIV-1 infection alone reveals another key dynamic. During HIV-1/Mtb co-infection, there is a delay in the viral load peak followed by a lower set point. This phenomenon is typically based on viral counts in the blood during the acute stage of HIV-1 infection. If viral titer in the blood is a good measurement of viral load in the lung, then we must examine why the lower set point is not observed during the HIV-1 infection alone. This is likely due to the fact that there are no fluctuations in the HIV-1 specific CTL population during the HIV only infection scenario. In fact, this appears to be the mechanism driving the lower viral set point in [8]. 

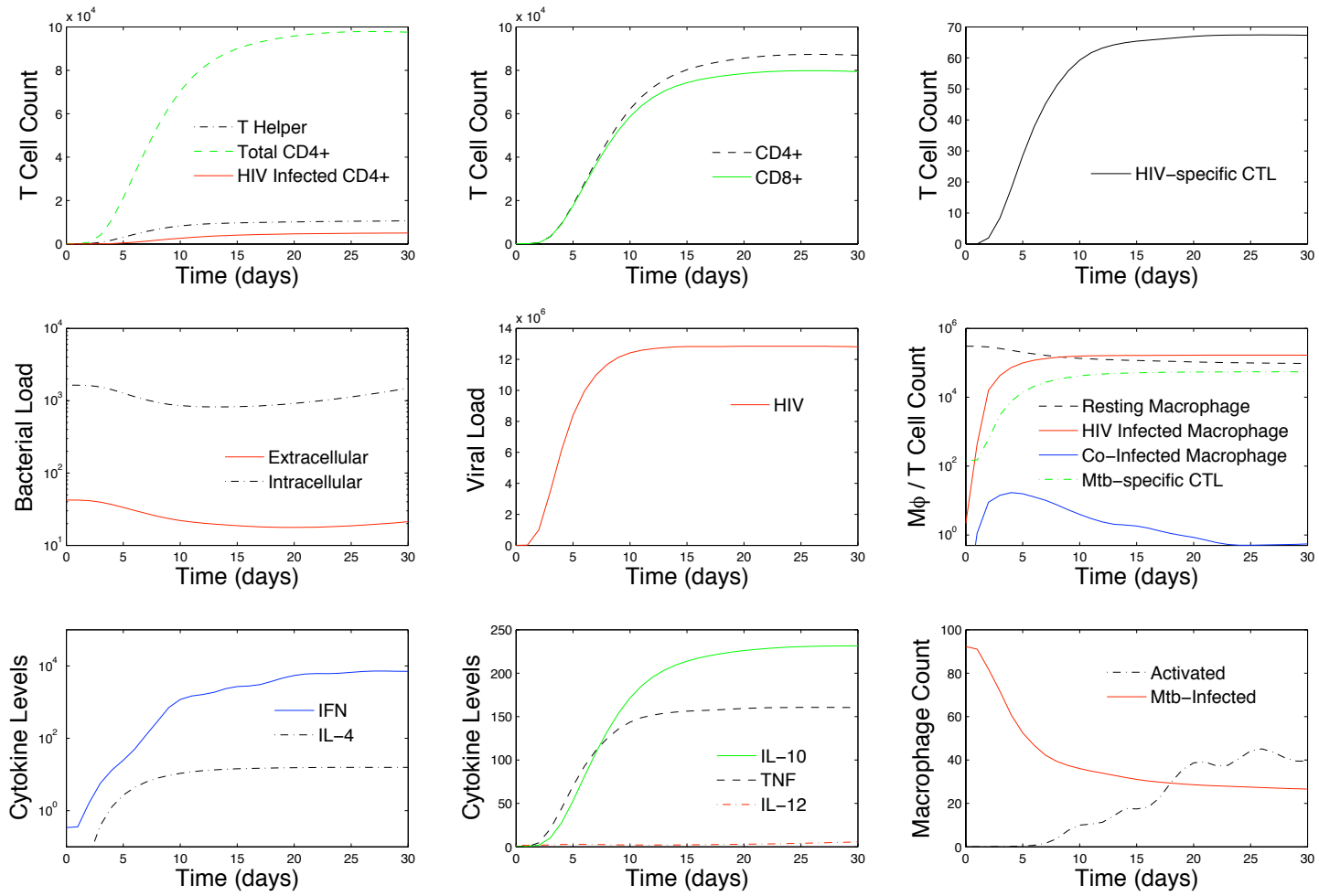

Figure 5: Numerical simulations of early dynamics of HIV-1/Mtb co-infection: 30 days after HIV1 infection of a host with latent TB. Parameter values are given in Tables 2-4. Units are measured in cells $/ \mathrm{mm}^{3}$ and $\mathrm{pg} / \mathrm{ml}$ for cytokine concentrations. 

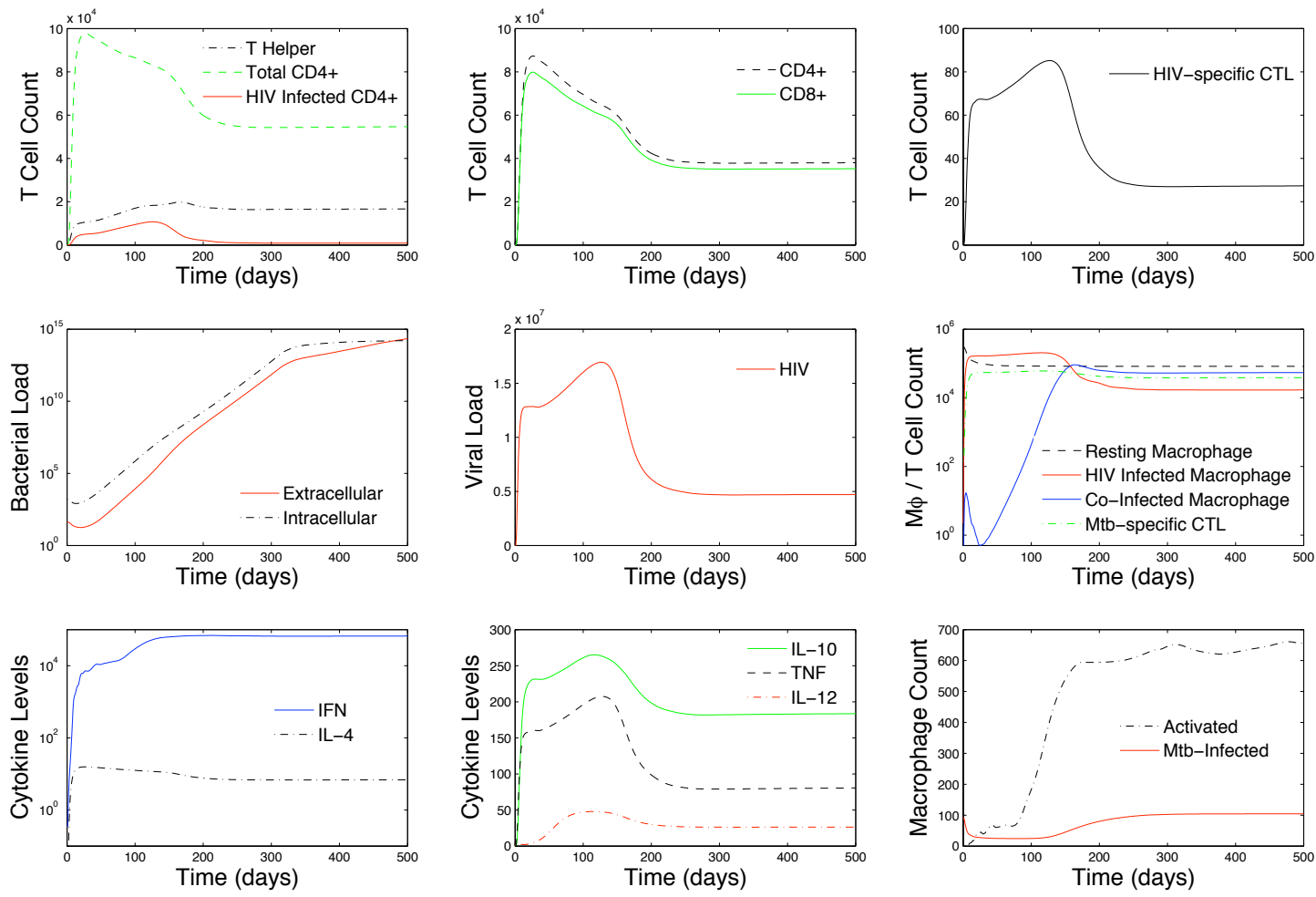

Figure 6: Numerical simulations of dynamics of HIV-1/Mtb co-infection: 500 days after HIV-1 infection of a host with latent TB. When co-infected with HIV-1, a host with latent TB is now unable to control bacterial growth. Parameter values are given in Tables 2-4. Units are measured in cells $/ \mathrm{mm}^{3}$ and $\mathrm{pg} / \mathrm{ml}$ for cytokine concentrations. 


\subsubsection{Identifying Parameters that Govern HIV-1/Mtb Co-Infection Dynamics}

We are interested in studying the mechanisms that are crucial to tuberculosis reactivation induced by HIV-1 infection. For this purpose we fix the TB related parameters to the values resulting in latent TB and vary only the HIV-1 related parameters (Table 3). This allows us to predict the mechanisms that induce reactivation of TB and how they affect the overall immune response in the co-infected situation. As one might expect, many of the same mechanisms that drive viral load and $\mathrm{CD} 4{ }^{+}$T-cell counts during HIV infection (e.g., virus infection rate of macrophages $\left(k_{M V}\right)$ and virus production rate by infected macrophages $\left(\Pi_{M}\right)$ ) also drive viral load during HIV-1/Mtb co-infection. We find that these mechanisms are, however, also positively correlated with total bacterial load $\left(B_{e}+B_{i}\right)$. This finding is consistent with the empirical evidence that co-infection reactivates TB infection. Our mechanistic model coupled with an analysis of this sort can suggest which mechanisms are responsible for HIV-1 induced TB reactivation. Table 8 shows those parameters that significantly (p-value $<0.01$ ) contribute to TB reactivation.

When we compare HIV-1 only infection (Table 7) with co-infection (Table 8), we find that macrophage dynamics become more significant. For example, the HIV-1 infection rate of resting macrophages, $k_{2 V}$, and CTL killing of HIV-1 infected and co-infected macrophages, $k_{52_{V}}$, both become significant. In addition, new co-infection mechanisms lead to increased viral load: the death rate of co-infected macrophages, $\mu_{M_{C}}$, and the viral infection rate of Mtb infected macrophages, $k_{M V}$. This suggests an important role for macrophages in co-infection dynamics. Interestingly, the signs and magnitude of the PRCCs for $\mu_{M_{C}}$ change for each of our outcome variables over the course of co-infection (Table 8 ). This suggests that initially (less than $\sim 100$ days) the death of co-infected macrophages works against the virus and in favor of recruiting $\mathrm{CD}^{+}{ }^{+} \mathrm{T}$-cells, but later in infection, the opposite is true. However, death of co-infected macrophages helps Mtb infection because it disseminates bacteria to spread Mtb infection.

In addition to macrophages playing a more prominent role in co-infection dynamics, infection and killing rates also have increased significance. CTL killing of HIV-1 infected and co-infected macrophages $\left(k_{52_{V}}\right)$ now has a negative impact on viral loads and total bacterial loads (Table 8). It also is negatively correlated with $\mathrm{CD} 4^{+} \mathrm{T}$-cells as they now become infected with the release of viral particles upon death of infected macrophages. Because of this reduction in T-cells, the host is less able to combat both infections. This points to the role of infected macrophages in speeding the progression of both HIV-1 and Mtb infections in co-infected hosts. The viral infection rate of Mtb infected macrophages $\left(k_{M V}\right)$ increases $\mathrm{CD} 4^{+} \mathrm{T}$-cell counts, viral loads and bacteria loads (see Table 8). This suggests that virus and bacteria do better in the co-infected system, each helping the other overcome the immune response.

During co-infection, different intitial viral loads $(V(0))$ affect total viral load $(V)$, total $\mathrm{CD}^{+}$ count $\left(T_{1}+T_{4}+T_{V}\right)$ and bacterial burden $\left(B_{T}\right)$ only in the first days post infection (see Table 9). The positive correlation with total viral load is strong the first 3-4 days post-infection with weak correlations even after 2 months post infection. On the other hand, the positive effect on total 
$\mathrm{CD}^{+}$T-cell counts is gone after one week, with its peak at 2-3 days. Results shown in Table 9 indicate different viral inocula have significant effects on total bacterial load. Initially (up to one week), we see a decrease in bacterial burden (negative correlation), with a peak between days 2-4. Later on during infection (at 2 and 6 months), the higher viral inoculum results in higher bacterial burden (positive correlation). One interesting observation is that the positive correlation between the initial viral titer $V(0)$ and $\mathrm{CD}_{4}{ }^{+}$T-cells closely mirrors the negative correlation between $V(0)$ and total bacterial load. This suggests that the initial recruitment of T-cells (and likely other immune cells), due to HIV-1 infection, helps to control Mtb infection initially. However, in very short order, we observe that an increase in initial viral load actually makes the HIV-1 and Mtb infection worse. This suggests that the virulence of the HIV-1 strain, or the magnitude of the initial exposure to HIV-1, may have an effect on the speed of co-infection progression.

\section{Conclusion and Future Directions}

It is clear that co-infection of HIV-1 and TB is a global health issue of increasing importance. Combined with the network for disease transmission that the rapid transport of people creates, and the increasing presence of multi-drug resistant TB rendering it basically incurable, HIV-1/Mtb co-infection becomes the largest known global health problem. In most cases, an individual will harbor latent TB prior to infection with HIV-1, rather than the opposite scenario. Thus, our focus in this work has been to examine the dynamics of co-infection and to predict what factors contribute to the reactivation of TB once HIV-1 infection occurs. Our model captures some of the key cellular dynamics that are observed during HIV-1/Mtb co-infection, including the reactivation of latent TB and more rapid progression to active disease, lower T-cell levels than in singly infected individuals, as well as decreasing $\mathrm{CD}^{+}{ }^{+}$and $\mathrm{CD}^{+} \mathrm{T}$-cell counts. Our results from analyzing the co-infected model suggest that macrophages play the central role in infection dynamics driving the system to disease. Thus, our work supports the hypothesis that therapies aimed at assisting macrophages in dealing with the double burden of mycobacteria and HIV-1 will have the greatest impact.

There are still some areas that can be explored with our model. For example, a study of SIV replication in macaque lung tissues indicates that there is not much local viral replication in the lungs during the earliest stages of HIV-1 infection [19], however, our model shows a sharp increase of virions in the lung. It is not clear why this is the case since the lung is a highly vascularized organ and there is likely to be virus there. Our model could be used to investigate under what conditions viremia in the lung persists, for example by including an intrinsic antiviral activity in the lung such as defensins or surfactants, or by more closely examining the role of infected macrophages in viral replication to see if macrophage infection controls the switch in the virus tropism (i.e., its choice of macrophages versus T-cells as the preferred host cell) during infection. Including additional physiological compartments, for example blood and lymph node, can assist in refining this model as we have done previously [48][49][35][36]. This model can then be used to test the effects of different treatment therapies on TB reactivation and the clinical progression of both TB and HIV 
in co-infected individuals.

\section{A. Appendix}

\section{A.1. Parameters}

Whenever possible, parameters are taken from experimental data. A list of all parameter values used in our model for numerical simulations is provided in the Tables below. Most parameter values are taken from [55], [8], and [27]. The following parameters were estimated specifically for this study. Two of these are related to TB/HIV co-infection, $\mu_{M_{C}}$ and $k_{V M}$. As there are very little data and numerical studies quantifying the kinetics of co-infection, we assume that the co-infected macrophage death rate $\left(\mu_{M_{C}}\right)$ and the rate at which HIV infected macrophages become infected with Mtb $\left(k_{V M}\right)$ are approximately equal to those during Mtb infection alone, i.e., $\mu_{M_{M}}$ and $k_{2 M}$ respectively. In addition, specific quantities for kinetic rates related to HIV-1 infected macrophages are also unobtainable in the literature, specifically $c_{52_{V}}$ and $k_{52_{V}}$. We estimate these parameters based on corresponding parameters available for Mtb infection alone, $c_{52_{M}}$ and $k_{52_{M}}$ respectively. The half-saturation constant related to the effect of IL- $\gamma$ on macrophage activation, $s_{1}$, is chosen to calibrate activated macrophage dynamics with those previously published [55]. We realize that these parameter estimates may or may not be accurate and that experimental verification is still needed. To understand to what degree these assumptions affect the relevance and reliability of our results, we include all estimated parameters in the sensitivity and uncertainty analysis.

Table 2: List of parameters not related to any specific pathogen.

\begin{tabular}{|c|c|c|c|}
\hline Parameter & Description & Model Value & Units \\
\hline$s_{M_{r}}$ & $\mathrm{M}_{r}$ recr rate & 1000 & $\mathrm{M}_{r} /$ day \\
\hline$s$ & $\mathrm{I}_{10}$ downreg by $\mathbf{M}_{a}$ prod $\mathrm{I}_{12}$ & 10 & $\mathrm{pg} / \mathrm{ml}$ \\
\hline$s_{\gamma}$ & NK $\mathrm{I}_{\gamma} \operatorname{prod}$ & 100 & $\mathrm{pg} / \mathrm{ml}$ day \\
\hline$s_{12}$ & $\mathrm{DC} \mathrm{I}_{12}$ prod & 300 & $\mathrm{pg} / \mathrm{ml}$ day \\
\hline$s_{4}$ & .5 sat: $\mathrm{I}_{12}$ on $\mathrm{I}_{10}$ & 50 & $\mathrm{pg} / \mathrm{ml}$ \\
\hline$s_{4 b}$ & .5 sat: $\mathrm{F}$ on $\mathrm{M}_{r}$ recr & 165 & $\mathrm{pg} / \mathrm{ml}$ \\
\hline$s_{4 b_{1}}$ & .5 sat: $\mathrm{F}$ on $\mathrm{Th} 1 \mathrm{recr}$ & 165 & $\mathrm{pg} / \mathrm{ml}$ \\
\hline$s_{4 b_{2}}$ & .5 sat: $\mathrm{F}$ on $\mathrm{T}_{4}$ recr & 450 & $\mathrm{pg} / \mathrm{ml}$ \\
\hline$s r_{1 B}$ & $\mathrm{~T}_{4} \mathrm{~F}$ indep recr & $1.75 \mathrm{e}^{5}$ & $\mathrm{~T}_{4} /$ day \\
\hline$s r_{3 B}$ & Th1 F indep recr & $2 \mathrm{e}^{4}$ & Th1/day \\
\hline$s r_{3 B_{c}}$ & $\mathrm{~K}, \mathrm{~T}_{8} \mathrm{~F}$ indep recr & $8 e^{4}$ & T/day \\
\hline$s r_{4 B}$ & $\mathrm{M}_{r} \mathrm{~F}$ indep recr & $2 e^{4}$ & $\mathrm{M}_{r} /$ day \\
\hline$s_{6}$ & .5 sat: $\mathrm{I}_{10}$ autocrine in $\mathrm{M}_{a}$ & 60 & $\mathrm{pg} / \mathrm{ml}$ \\
\hline$s_{7}$ & .5 sat: $\mathrm{I}_{12}$ on $\mathrm{I}_{\gamma}$ by $\mathrm{NK}$ & 40 & $\mathrm{pg} / \mathrm{ml}$ \\
\hline
\end{tabular}


Table 2 - Continued

\begin{tabular}{|c|c|c|c|}
\hline Parameter & Description & Model Value & Units \\
\hline$s_{8}$ & .5 sat: $\mathrm{I}_{10}$ on $\mathrm{M}_{a}$ deactiv & 1 & $\mathrm{pg} / \mathrm{ml}$ \\
\hline$\alpha_{1 A}$ & $\mathrm{~T}_{4} \mathrm{~F}$ indep recr & $5 e^{-3}$ & /day \\
\hline$\alpha_{11}$ & $\mathrm{~T}_{4} \mathrm{I}_{4}$ prod & $5 e^{-4}$ & /day \\
\hline$\alpha_{16}$ & Th1 $\mathrm{I}_{10}$ prod & $2 \mathrm{e}^{-3}$ & $\mathrm{pg} / \mathrm{Th} 1 \mathrm{day}$ \\
\hline$\alpha_{18}$ & $\mathrm{~K}, \mathrm{~T}_{8} \mathrm{I}_{10} \operatorname{prod}$ & $2 \mathrm{e}^{-2}$ & $\mathrm{pg} /(\mathrm{CD} 8 \mathrm{total})$ day \\
\hline$\alpha_{2}$ & $\max \mathrm{T}_{4} \mathrm{GR}$ & $5 e^{-3}$ & /day \\
\hline$\alpha_{23}$ & $\mathbf{M}_{r} \mathrm{I}_{12}$ prod & $2 \mathrm{e}^{-4}$ & $\mathrm{pg} / \mathrm{ml} \mathrm{M} M_{M}$ \\
\hline$\alpha_{3 A}$ & Th1 F indep recr & $5 e^{-3}$ & /day \\
\hline$\alpha_{3 A_{c}}$ & $\mathrm{~K}, \mathrm{~T}_{8} \mathrm{~F}$ indep recr & $3 e^{-3}$ & /day \\
\hline$\alpha_{4 A}$ & $\mathrm{M}_{r} \mathrm{~F}$ indep recr & $5 e^{-3}$ & /day \\
\hline$\alpha_{5 A}$ & Th1 $\mathrm{I}_{\gamma} \operatorname{prod}$ & 50 & $\mathrm{pg} / \mathrm{Th} 1 \mathrm{day}$ \\
\hline$\alpha_{5 B}$ & $\mathrm{CTL} \mathrm{I}_{\gamma}$ prod & 50 & $\mathrm{pg} / \mathrm{T}_{8}$ day \\
\hline$\alpha_{5 C}$ & $\mathbf{M}_{i} \mathrm{I}_{\gamma}$ prod & .03 & $\mathrm{pg} / \mathrm{ml} \mathrm{M}_{M}$ \\
\hline$\alpha_{7}$ & $\mathrm{~T}_{4} \mathrm{I}_{\gamma}$ prod & .03 & $\mathrm{pg} / \mathrm{ml} \mathrm{T}_{4}$ \\
\hline$\alpha_{8}$ & $\mathbf{M}_{a} \mathrm{I}_{12} \operatorname{prod}$ & $8 e^{-5}$ & $\mathrm{pg} / \mathrm{M}_{a}$ day \\
\hline$\delta_{6}$ & $\mathbf{M}_{a} \mathrm{I}_{10}$ prod & .01 & $\mathrm{pg} / \mathrm{ml} \mathrm{M}_{a}$ \\
\hline$c$ & .5 sat: $\mathrm{I}_{\gamma}$ on Th1 death & 1100 & $\mathrm{pg} / \mathrm{ml}$ \\
\hline$c_{10}$ & .5 sat: $\mathrm{BT}$ on $\mathrm{I}_{\gamma}$ by $\mathrm{NK}$ & $1 \mathrm{e}^{3}$ & $\mathrm{~B}_{T} / \mathrm{ml}$ \\
\hline$c_{15}$ & .5 sat: $\mathrm{M}_{a}$ on Th1 $\mathrm{I}_{\gamma}$ & $2 \mathrm{e}^{5}$ & $\mathrm{M}_{a}$ \\
\hline$c_{4}$ & .5 sat: $\mathrm{K}, \mathrm{Th} 1 / \mathrm{M}_{i}$ on $\mathrm{M}_{i}$ apop & 40 & $\mathrm{~T} / \mathrm{M}_{M}$ \\
\hline$c_{5 A}$ & .5 sat: $\mathrm{M}_{a}$ on $\mathrm{I}_{\gamma}$ by Th1 & $7 e^{3}$ & $\mathrm{M}_{a} / \mathrm{ml}$ \\
\hline$c_{5 B}$ & .5 sat: $\mathrm{M}_{a}$ on $\mathrm{I}_{\gamma}$ by $\mathrm{T}_{8}$ & $7 e^{3}$ & $\mathrm{M}_{a} / \mathrm{ml}$ \\
\hline$c_{c}$ & .5 sat: $\mathrm{I}_{\gamma}$ on $\mathrm{K}, \mathrm{T}_{8}$ death & 550 & $\mathrm{pg} / \mathrm{ml}$ \\
\hline$c_{T_{1}}$ & .5 sat: Th1 on $\mathrm{K}$ & 10 & Th1 \\
\hline$f_{4}$ & $\mathrm{I}_{10,12}$ on $\mathrm{I}_{\gamma}$ adj & 2 & scalar \\
\hline$f_{6}$ & $\mathrm{I}_{\gamma}$ on $\mathrm{I}_{10}$ adj & .025 & scalar \\
\hline$f_{7}$ & $\mathrm{I}_{10}$ effect on $\mathrm{I}_{\gamma} \mathrm{T}_{4}->\mathrm{Th} 1$ & 1 & scalar \\
\hline$f_{8}$ & $\mathrm{I}_{10} / \mathrm{F}$ on $\mathrm{M}_{r}$ adj & 1 & scalar \\
\hline$f_{9}$ & $\mathrm{~F} / \mathrm{I}_{10}$ adj & 50 & scalar \\
\hline$k_{4}$ & $\mathrm{I}_{10} \mathrm{M}_{a}$ deactiv & .08 & /day \\
\hline$k_{6}$ & $\max \mathrm{T}_{4}->\mathrm{Th} 1$ & $5 e^{-3}$ & $\mathrm{ml} / \mathrm{pg}$ day \\
\hline$w_{1}$ & $\max \%$ Th1 contr to toxic & .5 & \\
\hline$w_{2}$ & $\max \% \mathrm{M}_{i}$ prod chemok to $\mathrm{M}_{r}$ recr & .15 & \\
\hline$w_{3}$ & $\max \%$ Th1 contr to FasL apop of $\mathbf{M}_{i}$ & .4 & \\
\hline$\mu_{i 4}$ & $\mathrm{I}_{4}$ decay rate & 2.77 & /day \\
\hline$\mu_{i 10}$ & $\mathrm{I}_{10}$ decay rate & 5 & /day \\
\hline$\mu_{i 12}$ & $\mathrm{I}_{12}$ decay rate & 1.188 & /day \\
\hline & $\mathrm{I}_{\gamma}$ decay rate & 2.16 & /day \\
\hline
\end{tabular}


Table 2 - Continued

\begin{tabular}{llcl}
\hline Parameter & Description & Model Value & Units \\
\hline$\mu_{F}$ & TNF decay rate & 1.112 & $/$ day \\
$\mu_{M_{r}}$ & $\mathrm{M}_{r}$ death rate & .0033 & $/$ day \\
$\mu_{M_{a}}$ & $\mathrm{M}_{a}$ death rate & .07 & $/$ day \\
$\mu_{T_{1}}$ & $\mathrm{~T}_{1}$ death rate & .33 & $/$ day \\
$\mu_{T_{4}}$ & $\mathrm{~T}_{4}$ death rate & .33 & $/$ day \\
$\mu_{T_{8}}$ & $\mathrm{~T}_{8}$ death rate & .33 & $/$ day \\
$\mu_{T_{c_{\gamma}}}$ & $\mathrm{I}_{\gamma} \mathrm{T}_{8}$ apoptosis & $1 \mathrm{e}^{-4}$ & $/ \mathrm{M}_{a}$ day \\
$\mu_{T_{\gamma}}$ & $\mathrm{I}_{\gamma} \mathrm{T}_{1}$ apoptosis & $1 \mathrm{e}^{-4}$ & $/ \mathrm{M}_{a}$ day \\
$\beta_{1}$ & $\mathrm{TNF}$ scaling for $\mathrm{M}_{R}$ activation & $1 \mathrm{e}^{-3}$ & \\
\hline
\end{tabular}

\section{Acknowledgements}

This work was supported under grant numbers HL68526, HL72682, and LM00902701. 
Table 3: List of HIV and co-infection related parameters. All 29 parameters are included in LHSPRCC analysis of TB-HIV infections. Only 26 parameters are varied in LHS-PRCC analysis for HIV only infection ( $\mu_{M_{C}}, k_{M V}$ and $k_{V M}$ are discarded because they are related to co-infection). The initial viral load is also varied for the co-infection scenario (from 1 to 100 virions). Units are measured in cells $/ \mathrm{mm}^{3}$ and $\mathrm{pg} / \mathrm{ml}$ for cytokine concentrations.

\begin{tabular}{|c|c|c|c|c|}
\hline Parameter & Description & Model Value & Range & Units \\
\hline$s_{v}$ & $\mathrm{~V}$ interfer $\mathrm{w} / \mathrm{M}_{a} \mathrm{I}_{12}$ prod & $8 e^{6}$ & {$\left[1 \mathrm{e}^{4}-1 \mathrm{e}^{7}\right]$} & $\mathrm{V}$ \\
\hline$s_{v 1}$ & $\mathrm{~V}$ interfer $\mathrm{w} / \mathrm{T}_{1} \mathrm{I}_{10}$ prod & $8 e^{6}$ & {$\left[1 \mathrm{e}^{4}-1 \mathrm{e}^{7}\right]$} & $\mathrm{V}$ \\
\hline$s_{v 2}$ & $\mathrm{~V}$ interfer $\mathrm{w} / \mathrm{T}_{1} \mathrm{I}_{\gamma}$ prod & $8 e^{6}$ & {$\left[1 \mathrm{e}^{4}-1 \mathrm{e}^{7}\right]$} & $\mathrm{V}$ \\
\hline$s_{v 3}$ & $\mathrm{~V}$ enhance $\mathrm{T}_{1} \mathrm{~F}$ prod & $1 \mathrm{e}^{3}$ & {$\left[1 \mathrm{e}^{2}-1 \mathrm{e}^{4}\right]$} & $\mathrm{V}$ \\
\hline$\kappa$ & clearance rate of infected cells & $9 e^{-10}$ & {$\left[1 \mathrm{e}^{-11}-1 \mathrm{e}^{-9}\right]$} & /day cell \\
\hline$\chi_{T}$ & diff of $\mathrm{T}_{8}$ by $\mathrm{V}$ & $1 e^{-10}$ & {$\left[1 \mathrm{e}^{-12}, 1 \mathrm{e}^{-9}\right]$} & /day virion \\
\hline$\phi_{L}$ & $\mathrm{DC}$ recr due to $\mathrm{V}$ & $1 \mathrm{e}^{7}$ & {$\left[1 \mathrm{e}^{6}, 1 \mathrm{e}^{8}\right]$} & V \\
\hline$c_{1}$ & $\mathrm{~V}$ infected $\mathrm{T}_{4}$ & $10^{4}$ & {$\left[1 \mathrm{e}^{3}, 1 \mathrm{e}^{5}\right]$} & $\mathrm{K}$ \\
\hline$c_{3}$ & $\mathrm{~V}$ infected $\mathrm{T}_{1}$ & $10^{8}$ & {$\left[1 \mathrm{e}^{3}, 1 \mathrm{e}^{5}\right]$} & $\mathrm{K}$ \\
\hline$c_{5}$ & infected cell $\mathrm{V}$ prod & $10^{4}$ & {$\left[1 \mathrm{e}^{3}, 1 \mathrm{e}^{6}\right]$} & $\mathrm{K}$ \\
\hline$c_{52_{V}}$ & .5 sat: $\mathrm{K}$ on $\mathrm{M}_{V}$ killing & 50 & {$[1,100]$} & $\mathrm{K}$ \\
\hline$c_{V_{1}}$ & $\mathrm{~K}_{V}$ inhib on $\mathrm{M}_{V} \mathrm{~T}_{4}$ infec & $1 \mathrm{e}^{4}$ & {$\left[1 \mathrm{e}^{3}, 1 \mathrm{e}^{5}\right]$} & $\mathrm{K}_{V}$ \\
\hline$c_{V_{2}}$ & $\mathrm{~K}_{V}$ inhib on $\mathrm{M}_{V} \mathrm{~T}_{4}$ infec & $1 \mathrm{e}^{4}$ & {$\left[1 \mathrm{e}^{3}, 1 \mathrm{e}^{5}\right]$} & $\mathrm{K}_{V}$ \\
\hline$k_{1}$ & $\mathrm{~V}$ infect $\mathrm{T}_{4}$ & $9 e^{-11}$ & {$\left[1 \mathrm{e}^{-11}, 1 \mathrm{e}^{-10}\right]$} & /day virion \\
\hline$\hat{k}_{17}$ & .5 sat: $\mathrm{V}$ on $\mathrm{M}_{C}$ infec & $8 e^{6}$ & {$\left[1 \mathrm{e}^{5}, 1 \mathrm{e}^{7}\right]$} & $\mathrm{V}$ \\
\hline$k_{2 V}$ & $\mathrm{M}_{r} \mathrm{~V}$ infect rate & $6 e^{-8}$ & {$\left[6 \mathrm{e}^{-9}-6 \mathrm{e}^{-7}\right]$} & /day \\
\hline$k_{3 S}$ & $\mathrm{Th} 1 \mathrm{~V}$ infec rate & $4 e^{-11}$ & {$\left[4 \mathrm{e}^{-12}-4 \mathrm{e}^{-10}\right]$} & /day virion \\
\hline$k_{52_{V}}$ & cytotoxic $\mathrm{M}_{V}$ killing & .5 & {$\left[1 \mathrm{e}^{-2}-1\right]$} & /day \\
\hline$k_{V_{1}}$ & $\mathrm{~T}_{4}$ infec rate by mac & $4 e^{-13}$ & {$\left[1 \mathrm{e}^{-14}, 1 \mathrm{e}^{-10}\right]$} & /day cell \\
\hline$k_{V_{2}}$ & Th1 infec rate by mac & $2 e^{-7}$ & {$\left[1 \mathrm{e}^{-8}, 1 \mathrm{e}^{-6}\right]$} & /day cell \\
\hline$N_{V}$ & \# virions prod by $\mathrm{T}_{V}$ & 800 & {$\left[1 \mathrm{e}^{2}, 1 \mathrm{e}^{3}\right]$} & $\mathrm{V} / \mathrm{T}_{V}$ \\
\hline$\Pi_{M}$ & rate of $\mathbf{M}_{V}$ virion prod & 300 & {$[1,300]$} & /day \\
\hline$\mu_{c}$ & HIV spec CTL death & 1.5 & {$[0.2,2]$} & /day \\
\hline$\mu_{M_{V}}$ & $\mathrm{M}_{V}$ death rate & $5 e^{-3}$ & {$\left[1 \mathrm{e}^{-3}, 1 \mathrm{e}^{-1}\right]$} & /day \\
\hline$\mu_{T_{V}}$ & infected $\mathrm{T}_{V}$ death rate & .1 & {$[0.1,0.5]$} & /day \\
\hline$\mu_{V}$ & virion death & 3 & {$[1,5]$} & /day \\
\hline$\mu_{M_{C}}$ & $\mathrm{M}_{C}$ death rate & .0011 & {$\left[1 \mathrm{e}^{-3}, 1 \mathrm{e}^{-1}\right]$} & /day \\
\hline$k_{M V}$ & $\mathrm{M}_{M} \mathrm{~V}$ infect rate & $1 e^{-6}$ & {$\left[1 \mathrm{e}^{-7}-1 \mathrm{e}^{-5}\right]$} & /day \\
\hline$k_{V M}$ & $\mathbf{M}_{V}$ Mtb infect rate & .4 & {$[.01-2]$} & /day \\
\hline
\end{tabular}


Table 4: List of TB related parameters. All 29 parameters are included in LHS-PRCC analysis of TB only infection. Units are measured in cells $/ \mathrm{mm}^{3}$ and $\mathrm{pg} / \mathrm{ml}$ for cytokine concentrations.

\begin{tabular}{|c|c|c|c|c|}
\hline Parameter & Description & Model Value & Range & Units \\
\hline$\alpha_{19}$ & $\mathrm{~B}_{i} \mathrm{GR}$ & .4 & {$[.17-.6]$} & /day \\
\hline$\alpha_{20}$ & $\mathrm{~B}_{e} \mathrm{GR}$ & .05 & {$\left[1 \mathrm{e}^{-3}-.26\right]$} & /day \\
\hline$\beta_{2}$ & $\mathrm{~B}_{T}$ scaling for $\mathbf{M}_{a} \mathrm{~F}$ prod & $1 \mathrm{e}^{-3}$ & {$\left[1 \mathrm{e}^{-5}-1 \mathrm{e}^{-1}\right]$} & \\
\hline$c_{52_{M}}$ & .5 sat: $\mathrm{K}$ on $\mathrm{M}_{M}$ killing & 50 & {$\left[1,1 \mathrm{e}^{2}\right]$} & $\mathrm{K}$ \\
\hline$c_{8}$ & .5 sat: $\mathrm{B}_{T}$ on $\mathrm{M}_{r}$ act & $1 \mathrm{e}^{5}$ & {$\left[1 \mathrm{e}^{3}-1 \mathrm{e}^{7}\right]$} & $\mathrm{B}_{T} / \mathrm{ml}$ \\
\hline$c_{9}$ & .5 sat: $\mathrm{B}_{e}$ on $\mathrm{M}_{r}$ infec & $2 e^{6}$ & {$\left[1 \mathrm{e}^{4}, 5 \mathrm{e}^{7}\right]$} & $\mathrm{B}_{e}$ \\
\hline$k_{15}$ & $\mathrm{~B}_{e}$ killing by $\mathrm{M}_{a}$ & $1.25 \mathrm{e}^{-7}$ & {$\left[1 \mathrm{e}^{-8}, 1 \mathrm{e}^{-6}\right]$} & $\mathrm{ml} / \mathrm{M}_{a}$ day \\
\hline$k_{17}$ & $\operatorname{Max} \mathrm{M}_{i}$ from $\mathrm{B}_{i}$ & .02 & {$\left[1 \mathrm{e}^{-2}-.8\right]$} & /day \\
\hline$k_{18}$ & $\mathrm{~B}_{e}$ killing by $\mathrm{M}_{r}$ & $5 e^{-9}$ & {$\left[1 \mathrm{e}^{-10}, 1 \mathrm{e}^{-7}\right]$} & $\mathrm{ml} / \mathrm{M}_{r}$ day \\
\hline$k_{2 M}$ & $\mathbf{M}_{r}$ Mtb infect rate & .4 & {$\left[1 \mathrm{e}^{-2}, 1\right]$} & /day \\
\hline$k_{14 A}$ & Fas $\mathbf{M}_{M}$ apop & .1 & {$\left[1 \mathrm{e}^{-2}-.5\right]$} & /day \\
\hline$k_{14 B}$ & $\mathrm{~F} \mathrm{M}_{M}$ apop & .1 & {$\left[1 \mathrm{e}^{-2}-.5\right]$} & /day \\
\hline$k_{52_{N}}$ & Cytotoxic $\mathrm{M}_{M}$ killing & .5 & {$\left[1 \mathrm{e}^{-2}-1\right]$} & /day \\
\hline$N_{\text {frac a }}$ & Ave \# B/M $\mathrm{M}_{M}$ F-apop & .5 & {$[0.1,0.7]$} & scalar \\
\hline$N_{\text {frac c}_{\mathrm{c}}}$ & Ave \# B/M $\mathrm{M}_{M}$ Fas-apop & .1 & {$[0.01,0.3]$} & scalar \\
\hline$N$ & Carrying capacity of $\mathrm{M}_{M}$ & 20 & {$[10,50]$} & $\mathrm{B}_{i} / \mathrm{M}_{M}$ \\
\hline$\mu_{I}$ & $\mathrm{~B}_{i->} \mathrm{B}_{e}$ from $\mathrm{M}_{M}$ death & .004 & {$\left[1 \mathrm{e}^{-5}, 1 \mathrm{e}^{-2}\right]$} & /day \\
\hline$\mu_{M_{M}}$ & $\mathrm{M}_{M}$ death rate & .0011 & {$\left[1 \mathrm{e}^{-3}, 1 \mathrm{e}^{-1}\right]$} & /day \\
\hline$\mu_{T_{c}}$ & Mtb spec CTL death rate & .33 & {$\left[1 \mathrm{e}^{-3}, 0.5\right]$} & /day \\
\hline$\alpha_{30}$ & $\mathrm{M}_{M} \mathrm{~F}$ production & $3 e^{-3}$ & {$\left[2.5 \mathrm{e}^{-3}-1 \mathrm{e}^{-2}\right]$} & $\mathrm{pg} / \mathrm{ml} \mathrm{M}_{M}$ day \\
\hline$\alpha_{31}$ & $\mathrm{M}_{a} \mathrm{~F}$ production & $4 \mathrm{e}^{-3}$ & {$\left[1 \mathrm{e}^{-4}-1 \mathrm{e}^{-2}\right]$} & $\mathrm{pg} / \mathrm{ml} \mathrm{M}_{a}$ day \\
\hline$\alpha_{32}$ & Th1 F production & $8.16 \mathrm{e}^{-4}$ & {$\left[1 \mathrm{e}^{-5}-1 \mathrm{e}^{-3}\right]$} & $\mathrm{pg} / \mathrm{ml}$ Th1 day \\
\hline$\alpha_{33}$ & $\mathrm{~T}_{8} \mathrm{~F}$ production & $6 e^{-4}$ & {$\left[1 \mathrm{e}^{-6}-1 \mathrm{e}^{-4}\right]$} & $\mathrm{pg} / \mathrm{ml} \mathrm{T}_{8}$ day \\
\hline$f_{1}$ & $\mathrm{I}_{4, \gamma}$ adjustment & 200 & {$[10-150]$} & scalar \\
\hline$s_{10}$ & .5 sat: $\mathrm{I}_{\gamma}$ on $\mathrm{M}_{a} \mathrm{~F}$ prod & 80 & {$[1-200]$} & $\mathrm{pg} / \mathrm{ml}$ \\
\hline$k_{3}$ & $\mathrm{M}_{r}$ activation rate & .1 & {$\left[1 \mathrm{e}^{-4}-1\right]$} & /day \\
\hline$s_{1}$ & .5 sat: $\mathrm{I}_{\gamma}$ on $\mathrm{M}_{r}->\mathrm{M}_{a}$ & 2070 & {$[50-3000]$} & $\mathrm{pg} / \mathrm{ml}$ \\
\hline$c_{23}$ & .5 sat: $\mathrm{BT}$ on $\mathrm{I}_{12}$ by $\mathrm{M}_{r}$ & $5 \mathrm{e}^{3}$ & {$\left[1 \mathrm{e}^{3}-1 \mathrm{e}^{4}\right]$} & $\mathrm{BT} / \mathrm{ml}$ \\
\hline$c_{230}$ & .5 sat: $\mathrm{BT}$ on $\mathrm{I}_{12}$ by DC & $1 \mathrm{e}^{3}$ & {$\left[1 \mathrm{e}^{3}-1 \mathrm{e}^{4}\right]$} & $\mathrm{BT} / \mathrm{ml}$ \\
\hline
\end{tabular}


Table 5: Initial conditions for a healthy host, a host infected with Mtb only, HIV-1 only infection, and Mtb/HIV co-infection. Measure units are cells $/ \mathrm{mm}^{3}$ and $\mathrm{pg} / \mathrm{ml}$ for cytokine concentrations.

\begin{tabular}{|c|c|c|c|c|c|}
\hline Dependent Variable & Symbol & Healthy & TB only & HIV only & TB \& HIV \\
\hline Resting Macrophages & $M_{R}$ & $3 e^{5}$ & $3 e^{5}$ & $3 e^{5}$ & $3.063 \mathrm{e}^{5}$ \\
\hline Activated Macrophages & $M_{A}$ & 0 & 0 & 0 & 1 \\
\hline Mtb Infected Macrophages & $M_{M}$ & 0 & 0 & 0 & 52 \\
\hline HIV-1 Infected Macrophages & $M_{V}$ & 0 & 0 & 0 & 0 \\
\hline Co-Infected Macrophages & $M_{C}$ & 0 & 0 & 0 & 0 \\
\hline Th1 Helper T-cells & $T_{1}$ & 0 & 0 & 0 & 61 \\
\hline Resting CD4 ${ }^{+}$T-cells & $T_{4}$ & 0 & 0 & 0 & 196 \\
\hline Resting CD8 ${ }^{+}$T-cells & $T_{8}$ & 0 & 0 & 0 & 178 \\
\hline HIV-1 Infected CD4 ${ }^{+}$T-cells & $T_{V}$ & 0 & 0 & 0 & 0 \\
\hline HIV-1 Specific CTLs & $K_{V}$ & 0 & 0 & 0 & 0 \\
\hline Mtb Specific CTLs & $K_{M}$ & 0 & 0 & 0 & 243 \\
\hline HIV-1 Virions & $V$ & 0 & 0 & 10 & 10 \\
\hline Extracellular Bacteria & $B_{e}$ & 0 & 40 & 0 & 62 \\
\hline Intracellular Bacteria & $B_{i}$ & 0 & 0 & 0 & $3.65 \mathrm{e}^{3}$ \\
\hline TNF & $F$ & 0 & 0 & 0 & 0.1518 \\
\hline Interferon- $\gamma$ & $I_{\gamma}$ & 0 & 0 & 0 & 1.748 \\
\hline IL-10 & $I_{10}$ & 0 & 0 & 0 & 1.22 \\
\hline IL-12 & $I_{12}$ & 0 & 0 & 0 & 3.328 \\
\hline IL-4 & $I_{4}$ & 0 & 0 & 0 & 0.0354 \\
\hline
\end{tabular}

Table 6: Partial Rank Correlation Coefficients (PRCCs) of parameters listed in Table 4 with total bacterial load $\left(B_{e}+B_{i}\right)$ during Mtb infection. Only significant coefficients are listed (p-value $<$ $0.01)$.

\begin{tabular}{llrrrr}
\hline Parameter & Mechanism & 30 days & 100 days & 300 days & 500 days \\
\hline \hline$k_{17}$ & ${\text { Max } \mathbf{M}_{M} \text { bursting from } \mathbf{B}_{i}}-0.38$ & -0.36 & -0.31 & -0.29 \\
$c_{9}$ & Half sat: $\mathbf{B}_{e}$ on $\mathbf{M}_{r}$ infect & 0.42 & 0.41 & 0.35 & 0.32 \\
$k_{2 M}$ & $\mathbf{M}_{r}$ Mtb infection rate & -0.36 & -0.43 & -0.36 & -0.36 \\
$N$ & ${\text { Carrying capacity of } \mathbf{M}_{M}}$ & -0.35 & -0.2 & -0.21 & -0.22 \\
$\alpha_{30}$ & $\mathbf{M}_{M}$ TNF production & & -0.12 & & \\
$\alpha_{20}$ & $\mathrm{~B}_{e}$ growth rate & 0.21 & 0.44 & 0.45 & 0.46 \\
$\alpha_{19}$ & B $_{i}$ growth rate & 0.24 & & & \\
$k_{52 M}$ & Cytotoxic $\mathbf{M}_{M}$ killing & -0.14 & & & 0.12 \\
$s_{10}$ & Half sat: $\mathrm{I}_{\gamma}$ on $\mathbf{M}_{a}$ F prod & & 0.12 & & \\
\hline
\end{tabular}


Table 7: Partial Rank Correlation Coefficients (PRCCs) of parameters listed in Table 3 with total viral load $(V)$ and $C D 4^{+}$count $\left(T_{1}+T_{4}+T_{V}\right)$ during HIV-1 infection. Only significant coefficients are listed (p-value $<0.01)$.

\begin{tabular}{llrrrr}
\hline Outcome $=$ & Viral Load & & & & \\
\hline Parameter & Mechanism & 30 days & 100 days & 300 days & 500 days \\
\hline \hline$s_{v 1}$ & V interfer w/ $\mathrm{T}_{1} \mathrm{I}_{10}$ prod & 0.16 & 0.17 & 0.18 & 0.19 \\
$c_{52_{V}}$ & Half sat: K on $\mathrm{M}_{V}$ killing & & 0.15 & 0.14 & 0.14 \\
$k_{2 V}$ & $\mathrm{M}_{r}$ V infection rate & 0.3 & 0.16 & & \\
$\Pi_{M}$ & ${\text { Rate of } \mathrm{M}_{V} \text { virion prod }}$ & 0.86 & 0.85 & 0.87 & 0.88 \\
$\mu_{M_{V}}$ & M $_{V}$ death rate & -0.66 & -0.86 & -0.89 & -0.89 \\
$\mu_{V}$ & Virion death & -0.69 & -0.7 & -0.73 & -0.73 \\
$k_{52_{V}}$ & Cytotoxic $\mathrm{M}_{V}$ killing & -0.12 & & & \\
\hline
\end{tabular}

\begin{tabular}{llrrrr}
\hline Outcome $=$ & Total CD4 ${ }^{+}$T-cells & & & & \\
\hline Parameter & Mechanism & 30 days & 100 days & 300 days & 500 days \\
\hline \hline$c_{52_{V}}$ & Half sat: K on $\mathbf{M}_{V}$ killing & & 0.16 & 0.17 & 0.18 \\
$k_{2 V}$ & M $_{r}$ V infection rate & 0.42 & 0.25 & 0.23 & 0.21 \\
$\Pi_{M}$ & ${\text { Rate of } \mathrm{M}_{V} \text { virion prod }}$ & 0.4 & 0.15 & 0.14 & \\
$\mu_{M_{V}}$ & $\mathrm{M}_{V}$ death rate & -0.73 & -0.9 & -0.93 & -0.94 \\
$s_{v 3}$ & $\mathrm{~V}$ enhance $\mathrm{T}_{1} \mathrm{~F}$ prod & & -0.13 & &
\end{tabular}


Table 8: Partial Rank Correlation Coefficients (PRCCs) of parameters listed in Table 3 with total viral load $(V)$, total $\mathrm{CD}^{+}{ }^{+}$count $\left(T_{1}+T_{4}+T_{V}\right)$ and bacterial burden $\left(B_{T}\right)$ during co-infection. Only significant coefficients are listed (p-value $<0.01$ ).

\begin{tabular}{|c|c|c|c|c|c|}
\hline Outcome $=$ & Viral Load & & & & \\
\hline Parameter & Mechanism & 30 days & 100 days & 300 days & 500 days \\
\hline$c_{52_{V}}$ & 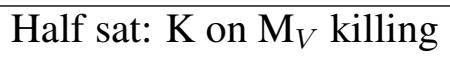 & 0.08 & 0.1 & 0.1 & 0.08 \\
\hline$k_{2 V}$ & $\mathrm{M}_{r} \mathrm{~V}$ infection rate & 0.38 & 0.66 & 0.4 & 0.28 \\
\hline$k_{52_{V}}$ & Cytotoxic $\mathrm{M}_{V}$ killing & -0.16 & -0.22 & -0.2 & -0.19 \\
\hline$\Pi_{M}$ & Rate of $\mathrm{M}_{V}$ virion prod & 0.47 & 0.77 & 0.74 & 0.72 \\
\hline$\mu_{M_{V}}$ & $\mathrm{M}_{V}$ death rate & -0.17 & & -0.2 & -0.33 \\
\hline$\mu_{M_{C}}$ & $\mathbf{M}_{C}$ death rate & -0.11 & 0.18 & 0.18 & 0.17 \\
\hline$\mu_{V}$ & Virion death & -0.3 & -0.5 & -0.55 & -0.54 \\
\hline$k_{M V}$ & $\mathrm{M}_{M} \mathrm{~V}$ infection rate & 0.24 & 0.24 & 0.22 & 0.23 \\
\hline$V(0)$ & Initial viral load & 0.11 & 0.10 & & \\
\hline
\end{tabular}

\begin{tabular}{|c|c|c|c|c|c|}
\hline Outcome $=$ & Total CD4 ${ }^{+}$T-cells & & & & \\
\hline Parameter & Mechanism & 30 days & 100 days & 300 days & 500 days \\
\hline$c_{52_{V}}$ & "Half sat: $\mathrm{K}$ on $\mathrm{M}_{V}$ killing & 0.12 & 0.17 & 0.21 & 0.22 \\
\hline$k_{2 V}$ & $\mathrm{M}_{r} \mathrm{~V}$ infection rate & 0.24 & 0.19 & 0.11 & 0.12 \\
\hline$k_{52_{V}}$ & Cytotoxic $\mathrm{M}_{V}$ killing & -0.2 & -0.24 & -0.33 & -0.33 \\
\hline$\Pi_{M}$ & Rate of $\mathrm{M}_{V}$ virion prod & 0.38 & 0.3 & 0.15 & 0.15 \\
\hline$\mu_{M_{V}}$ & $\mathbf{M}_{V}$ death rate & -0.56 & -0.65 & -0.09 & -0.08 \\
\hline$\mu_{M_{C}}$ & $\mathbf{M}_{C}$ death rate & 0.17 & 0.21 & -0.38 & -0.39 \\
\hline$\mu_{V}$ & Virion death & -0.16 & -0.13 & & \\
\hline$k_{M V}$ & $\mathrm{M}_{M} \mathrm{~V}$ infection rate & 0.18 & 0.19 & 0.20 & 0.19 \\
\hline Outcome $=$ & Total Bacterial Load & & & & \\
\hline Parameter & Mechanism & 30 days & 100 days & 300 days & 500 days \\
\hline$c_{52_{V}}$ & Half sat: $\mathrm{K}$ on $\mathrm{M}_{V}$ killing & 0.09 & 0.32 & 0.25 & 0.25 \\
\hline$k_{2 V}$ & $\mathrm{M}_{r} \mathrm{~V}$ infect rate & & 0.41 & 0.39 & 0.37 \\
\hline$k_{52_{V}}$ & Cytotoxic $\mathrm{M}_{V}$ killing & -0.16 & -0.51 & -0.33 & -0.33 \\
\hline$\Pi_{M}$ & Rate of $\mathrm{M}_{V}$ virion prod & 0.26 & 0.71 & 0.66 & 0.63 \\
\hline$\mu_{M_{V}}$ & $\mathbf{M}_{V}$ death rate & & & -0.34 & -0.27 \\
\hline$\mu_{M_{C}}$ & $\mathbf{M}_{C}$ death rate & 0.33 & 0.62 & & \\
\hline$\mu_{V}$ & Virion death & & -0.38 & -0.45 & -0.42 \\
\hline$k_{M V}$ & $\mathrm{M}_{M} \mathrm{~V}$ infect rate & 0.22 & 0.61 & 0.54 & 0.53 \\
\hline$V(0)$ & Initial viral load & & 0.13 & & \\
\hline
\end{tabular}


Table 9: PRCCs of different initial viral loads $(V(0))$ on total viral load $(V)$, total $\mathrm{CD}^{+}{ }^{+}$count $\left(T_{1}+T_{4}+T_{V}\right)$ and bacterial burden $\left(B_{T}\right)$ during co-infection in the first days post infection. Only significant coefficients are listed (p-value $<0.01)$.

\begin{tabular}{llrrrrrr}
\hline Outcome & 1 day & 2 days & 3 days & 4 days & 1 wk & 60 days & 180 days \\
\hline \hline Viral load & 0.75 & 0.53 & 0.38 & 0.3 & 0.18 & 0.11 & \\
Total CD4 $^{+}$ & 0.08 & 0.35 & 0.26 & 0.19 & 0.11 & & \\
Total bacterial load & -0.1 & -0.39 & -0.3 & -0.22 & -0.1 & 0.1 & 0.08
\end{tabular}




\section{References}

[1] CDC National Prevention Information Network.

[2] National Institute of Allergy and Infectious Disease.

[3] Global Tuberculosis Control. Surveillance, Planning, Financing. World Health Organization Report, 2003.

[4] A deadly partnership: Tuberculosis in the era of HIV. World Health Organization. Global Tuberculosis Programme. World Health Organization Consensus Statement, Geneva. 2002.

[5] H.M. Algood, P.L. Lin, D. Yankura, A. Jones, J. Chan, J.L. Flynn. TNF influences chemokine expression of macrophages in vitro and that of CD11b+cells in vivo during Mycobacterium tuberculosis infection. J. Immun., 172 (2004), 6846-6857.

[6] V. Appay, J.J. Zaunders, I. Papagno, J. Sutton, A. Jaramillo, A. Waters, P. Easterbrook, P. Grey, D. Smith, A.J. McMichael, D.A. Cooper, S.L. Rowland-Jones, A.D. Kelleher. Characterization of CD4+ CTLs ex vivo. J. Immun., 168 (2002), 5954-5958.

[7] P. Bacchetti, A.R. Moss. Incubation period of AIDS in San Francisco. Nature, 338 (1989), 251-253.

[8] S.H. Bajaria, D.E. Kirschner. CTL action during HIV-1 is determined via interactions with multiple cell types. Deterministic and Stochastic Models for AIDS Epidemics and HIV Infection with Interventions. Ed. W.Y. Tan and H. Wu. World Scientific, 2005, 219-254.

[9] G.M. Bonecini-Almeida, S. Chitale, I. Boutsikakis, J. Geng, H. Doo, S. He, J.L. Ho. Induction of in vitro human macrophage anti-M. tuberculosis activity: requirement for IFN- $\gamma$ and primed lymphocytes. J. Immun., 160 (1998), 4490-4499.

[10] G. Canetti. The Tubercule Bacillus in the Pulmonary Lesion in Man. Springer Publishing Co., New York, 1955.

[11] A. Ciaramella, A. Cavone, M.B. Santucci, M. Amicosante, A. Martino, G. Auricchio, L.P. Pucillo, V. Colizzi, M. Fraziano. Proinflammatory cytokines in the course of Mycobacterium tuberculosis-induced apoptosis in macrophages/monocytes. J. Infect. Dis., 186 (2002), 1277 1282 .

[12] G.W. Comstock. Epidemiology of tuberculosis. Am. Rev. Respir. Dis., 125 (1982), 8-15.

[13] E.L. Corbett, C.J. Watt, N. Walker, D. Maher, B.G. Williams, M.C. Raviglione, C. Dye. The growing burden of tuberculosis: global trends and interactions with the HIV epidemic. Arch. Int. Med., 163 (2003), No. 9, 1009-1021. 
[14] G. D’Amico, G. Frascaroli, G. Bianchi, P. Transidico, A. Doni, A. Vecchi, S. Sozzani, P. Allavena, A. Mantovani. Uncoupling of inflammatory chemokine receptors by IL-10: generation of functional decoys. Nat. Immun., 1 (2000), 387-391.

[15] D.K. Dalton, L. Haynes, C.Q. Chu, S.L. Swain, S. Wittmer. Interferon gamma eliminates responding CD4 $T$ cells during Mycobacterial infection by inducing apoptosis of activated CD4 T cells. J. Exp. Med., 192 (2000), 117-122.

[16] G. Del Prete, M. Almerigogna, M. Giudizi. Human IL-10 is produced by both type 1 helper (Th1) and type 2 helper (Th2) T cell clones and inhibits their antigen-specific proliferation and cytokine production. J. Immunol., 150 (1993), 353-360.

[17] J.L. Flynn, M.M. Goldstein, J. Chan, K.J. Triebold, K. Pfeffer, C.J. Lowenstein, R. Screiber, T.W. Mak, B.R. Bloom. Tumor necrosis factor- $\alpha$ is required in the protective immune response to Mycobacterium tuberculosis. Immunity, 2 (1995), 561-572.

[18] J.L. Flynn, J. Chan. Tuberculosis: latency and reactivation. Infect. Immun., 69 (2001), No. 7, 4195-4201.

[19] C.L. Fuller, Y.K. Choi, B.A. Fallert, S. Capuano III, P. Rajakumar, M. Murphey-Corb, T.A. Reinhart. Restricted SIV replication in rhesus macaque lung tissues during the acute phase of infection. Am. J. Path., 161 (2002), No. 3, 969-978.

[20] S.A. Fulton, J.M. Johnson, S.F. Wolf, D.S. Sieburth, W.H. Boom. Interleukin-12 production by human monocytes infected with Mycobacterium tuberculosis, role of phagocytosis. Infect. Immun., 64 (1996), 2523-2531.

[21] R.T. Gazinelli, I.P. Oswald, S.L. James, A. Sher. IL-10 inhibits parasite killing and nitrogen oxide production by IFN- $\gamma$ activated macrophages. J. Immunol., 148 (1992), No. 6, 17921796.

[22] R. Geiben-Lynn. Anti-human immunodeficiency virus noncytolytic CD8+ T-cell response: A review. AIDS patient care STDS, 16 (2002), No. 10, 471-477.

[23] D. Goletti, D. Weissman, R.W. Jackson, N.M. Graham, D. Vlahov, R.S. Klein, S.S. Munsiff, L. Ortona, R. Cauda, A.S. Fauci. Effect of Mycobacterium tuberculosis on HIV replication. J. Immun., 157 (1996), 1271-1278.

[24] S.P. Hickman, J. Chan, P. Salgame. Mycobacterium tuberculosis induces differential cytokine production from dendritic cells and macrophages with divergent effects on naive T cell polarization. J. Immun., 168 (2002), 4636-4642.

[25] D.D Ho. Viral counts count in HIV infection. Science, 272 (1996), No. 5265, 1124-1125.

[26] J. Keane, H.G. Remold, H. Kornfeld. Virulent Mycobacterium tuberculosis strains evade apoptosis of infected aveolar macrophages. J. Immun., 164 (2000), 2016-2020. 
[27] D.E. Kirschner, A. Perelson. A model for the immune system response to HIV: AZT treatment studies. Mathematical Population Dynamics: Analysis of Heterogeneity and Theory of Epidemics. Editors: O. Arino, D. Axelrod, M. Kimmel, M. Langlais. Wuerz Publishing, 1 (1995), 295-310.

[28] D.E. Kirschner. Dynamics of co-infection with M. tuberculosis and HIV-1. Theor. Pop. Biol., 55 (1999), 94-109.

[29] A.P. Junqueira-Kipnis, A. Kipnis, A. Jamieson, M.G. Juarrero, A. Diefenbach, D.H. Raulet, J. Turner, I.M. Orme. NK cells respond to pulmonary infection with Mycobacterium tuberculosis, but play a minimal role. J. Immun., 171 (2003), 6039-6045.

[30] R. Lalvani, R. Brookes, R.J. Wilkinson, A.S. Malin, A.A. Kpathan, P. Andersen, H. Dockrell, G. Pasvol, A.V.S. Hill. Human cytolytic and interferon $\gamma$-secreting T lymphocytes specific for Mycobacterium tuberculosis. Proc. Natl. Acad. Sci. USA, 95 (1998), 270-275.

[31] V. Lazarevic, D. Nolt, J.L. Flynn. Long term control of Mycobacterium tuberculosis infection is mediated by dynamic immune responses. J. Immun., 175 (2005), 1107-1117.

[32] E. Maggi, F. Almerigogna, G. Del Prete, S. Romagnani. Abnormal B cell help by virusinfected T cells. Seminars in Immun., 5 (1993), 449-455.

[33] R. Manetti, P. Parronchia, M. Giudizi, M. Piccinni, E. Maggi, G. Trinchieri, S. Romangnani. Natural killer cell stimulatory factor (interleukin-12 (IL-12)) induces Thelper type 1 (Th1)specific immune responses and inhibits the development of IL-4 producing Th cells. J. Exp. Med., 177 (1993), 1199-1204.

[34] M.D. McKay, R.J. Beckman, W.J. Conover. A comparison of three methods for selecting values of input variables in the analysis of output from a computer code. Technometrics, 42 (2000), No. 1, 55-61.

[35] S. Marino, D.E. Kirschner. The human immune response to Mycobacterium tuberculosis in lung and lymph node. J. Theor. Biol., 227 (2004), No. 4, 463-486.

[36] S. Marino, S. Pawar, C.L. Fuller, T.A. Reinhart, J.L. Flynn, D.E. Kirschner. Dendritic cell trafficking and antigen presentation in the human immune response to Mycobacterium tuberculosis. J. Immunol., 173 (2004), No. 1, 494-506.

[37] S. Marino, D. Sud, H. Plessner, P.L. Lin, J. Chan, J.L. Flynn, D.E. Kirschner. Differences in reactivation of tuberculosis induced from anti-TNF treatments are based on bioavailability in granulomatous tissue. PLOS Comput. Biol., 3 (2007), No. 10, e194.

[38] S. Marino, I. Hogue, C.J. Ray, D.E. Kirschner. A methodology for performing global uncertainty and sensitivity analysis in systems biology J. Theor. Biol., (2008) in press. 
[39] D.J. Martin, J.G. Sim, G.J. Sole, L. Rymer, S. Shalekoff, A.B. van Niekerk, P. Becker, C.N. Weilbach, J. Iwanik, K. Keddy. Lymphocyte count in in African patients co-infected with HIV and tuberculosis. JAIDS, 8 (1995), No. 4, 386-391.

[40] National Association of Manufacturers, Factsheet 20. 2005.

[41] National Association of Manufacturers, Factsheet 44. 2005.

[42] G.W. Newman, T.G. Kelley, H. Gan, O. Kandil, M.J. Newman, P. Pinkston, R.M. Rose, H.G. Remold. Concurrent infection of human macrophages with HIV-1 and Mycobacterium avium results in decreased cell viability, increased $M$. avium multiplication and altered cytokine production. J. Immunol., 151 (1993), 2261-2272.

[43] P. Nunn, B. Williams, K. Floyd, C. Dye, G. Elzinga, M. Raviglione. Tuberculosis control in the era of HIV. Nature Rev. Immun., 5 (2005), 819-826.

[44] N. Oyaizu, N. Chirmule, V.S. Kalyanaraman, W.W. Hall, R.A. Good, S. Pahwa. Human immunodeficiency virus type 1 envelope glycoprotein gp120 produces immune defects in $\mathrm{CD}^{+}$ T lymphocytes by inhibiting interleukin 2 mRNA. Proc. Natl. Acad. Sci. USA, 87 (1990), 2379-2383.

[45] T.A. Reinhart, M.J. Rogan, D. Huddleston, D.M. Rausch, L.E. Eiden, A.T. Hasse. Simian immunodeficiency virus burden in tissues and cellular compartments during clinical latency and AIDS. J. Inf. Dis., 176 (1997), 1198-1208.

[46] D.S.S. Rodrigues, R.M.C. Cunha, E.G. Kallas, R. Salomao. Distribution of naive and memory/effector CD4+ T lymphocytes and expression of CD38 on CD8+ T lymphocytes in AIDS patients with Tuberculosis. Braz. J. Infect. Dis., 7 (2003), 161-165.

[47] P.M. Roger, L.E. Bermudez. Infection of mice with Mycobacterium avium primes CD8 ${ }^{+}$lymphocytes for apoptosis upon exposure to macrophages. Clin. Immun., 99 (2001), 378-386.

[48] S.H. Bajaria, G. Webb, M. Cloyd, D.E. Kirscher. Dynamics of Naive and Memory CD4+ T Lymphocytes in HIV-1 Disease Progression. J. AIDS and Hum. Retrov., 30 (2002), 41-58.

[49] S.H. Bajaria, G. Webb, D.E. Kirschner. Predicting Differential Responses to Structured Treatment Interruptions During HAART. Bull. Math Biol., 66 (2004), 1093-1118.

[50] R.J. Shattock, J.S. Friedland, G.E. Griffin. Modulation of HIV transcription in and release from human monocytic cells following phagocytosis of Mycobacterium tuberculosis. Res. Virol., 144 (1993), No. 1, 7-12.

[51] M.A. Skinner, S. Yuan, R. Prestidge, D. Chuk, J.D. Watson, P.L.J. Tan. Immunization with heat-killed Mycobacterium vaccae stimulates $C D 8^{+}$cytotoxic $T$ cells specific for macrophages infected with Mycobacterium tuberculosis. Infect. Immun., 65 (1997), No. 11, 4525-4530. 
[52] J.F.D. Siawaya, M. Ruhwald, J. Eugen-Olsen, G. Walzl. Correlates for desease progression and prognosis during cuncurrent HIV/TB infection. Int. J. Infect. Dis., 11 (2007), 289-299.

[53] S. Stenger, R. Mazzaccaro, K. Uyemura, S. Cho, P. Barnes, J. Rosat, A. Sette, M. Brenner, S.A. Porcelli, B.R. Bloom, R.L. Modlin. Differential effects of cytolytic T cell subsets on intracellular infection. Science, 276 (1997), 1684-1687.

[54] S. Stenger, D.A. Hanson, R. Teitelbaum, P. Dewan, K.R. Niazi, C.J. Froelich, T. Ganz, S. Thoma-Uszynski, A. Melian, C. Bogdan, S.A. Porcelli, B.R. Bloom, A.M. Krensky, R.L. Modlin. An antimicrobial activity of cytolytic T cell subsets mediated by granulysin. Science, 282 (1998), 121-125.

[55] D. Sud, C. Bigbee, J.L. Flynn, D.E. Kirschner. Contribution of $C D 8^{+} T$ cells to control of Mycobacterium tuberculosis infection. J. Immun., 176 (2006), 4296-4314.

[56] M.C. Tsai, S. Chakravarty, G. Zhu, J. Xu, K. Tanaka, C. Koch, J. Tufariello, J.L. Flynn, J. Chan. Characterization of the tuberculous granuloma in murine and human lungs: cellular composition and relative tissue oxygen tension. Cell Microbiol., 8 (2006), No. 2, 218-232.

[57] S.M. Wahl, T. Greenwell-Wild, H. Hale-Donze, N. Moutsopoulos, J.M. Orenstein. Permissive factors for HIV-1 infection of macrophages. J. Leuk. Biol., 68 (2000), 303-310.

[58] J. Wigginton, D.E. Kirschner. A model to predict cell-mediated immune regulatory mechanisms during human infection with Mycobacterium tuberculosis. J. Immun., 166 (2001), 1951-1976. 